\title{
Assessing intra-annual vegetation regrowth after fire using the pixel based regeneration index
}

\author{
S. Lhermitte ${ }^{*, a, b}$, J. Verbesselt ${ }^{\mathrm{c}}$, W.W. Verstraeten ${ }^{\mathrm{b}}$, S. Veraverbeke $^{\mathrm{d}}$, P. \\ Coppin $^{\mathrm{b}}$ \\ ${ }^{a}$ Centro de Estudios Avanzados en Zonas Aridas (CEAZA), Universidad de la Serena, \\ La Serena, Chile \\ ${ }^{b}$ M3-BIORES, Biosystems Department, Katholieke Universiteit Leuven, Leuven, Belgium \\ ${ }^{c}$ CSIRO, 3169 Clayton South, Melbourne, Australia \\ ${ }^{d}$ Department of Geography, Ghent University, Ghent, Belgium
}

\section{Abstract}

Several remote sensing studies have discussed the potential of satellite imagery as an alternative for extensive field sampling to quantify fire-vegetation impact over large areas. Most studies depend on Landsat image availability with infrequent image acquisition dates and consequently are limited for assessing intra-annual fire-vegetation dynamics or comparing different fire plots and dates. The control pixel based regeneration index (pRI) derived from SPOT-Vegetation (VGT) normalized difference vegetation index (NDVI) is used in this study as an alternative to the traditional bi-temporal Landsat approach based on the normalized burn ratio (NBR). The major advantage of the pRI is the use of unburnt control plots which allow to express the intraannual variation due to regeneration processes without external influences. In the comparison of Landsat and VGT data, (i) the inter-annual differences between the bi-temporal and control plot approach were contrasted and (ii)

\footnotetext{
${ }^{*}$ Corresponding author. Tel: +56982454633 ; Fax: +5651334741 .

Email address: stef.1hermitte@gmail.com (S. Lhermitte)
} 
metrics of pRI were derived and compared with the inter-annual dynamics of both VGT and Landsat data. Results of these comparisons, demonstrate the overall similarity between NBR and NDVI data, stress the importance of the elimination of external influences (e.g., phenological variations), and emphasize the failure of including post-fire vegetation responses in bi-temporal Landsat assessments, especially in quickly recovering ecotypes with a strong annual phenological cycle such as savanna. This highlights the importance of using high frequent multi-temporal approaches to estimate fire-vegetation impact in temporally dynamic vegetation types.

Key words: wildfires, burn severity, savanna woodland, fire-vegetation impact, time series analysis, remote sensing, SPOT Vegetation 


\section{Introduction}

Wildfires play an essential role in several ecological processes since they partially or completely remove the vegetation layer. This biomass burning has several effects at a variety of spatial and temporal scales. At the microscale level, fires affect soil structure, plant nutrition, species composition and competition (Reilly et al., 2006; Kokaly et al., 2007; Fox et al., 2008), whereas at the landscape level, fire disturbances result in changes in composition, structure and function of ecosystems (Eva and Lambin, 2000; Viedma, 2008). On regional to global scales fire can result in changes in vegetation distribution and in atmospheric chemistry as they represent a significant source of trace gases and aerosol particles (Hoelzemann et al., 2004; Van Der Werf et al., 2003). As such, they have a major influence on the global ecosystem distribution (Ehrlich et al., 1997) and affect the global climate (Running, 2008). Besides the different effects across spatial scales, the temporal impact of fires can also vary considerably. For example, in savanna ecosystems vegetation can completely recover in a matter of weeks (Eckhardt et al., 2000; Eva and Lambin, 2000), whereas forest regeneration after burning can take years to centuries (Nepstad et al., 1999). This also shows how fire impact and vegetation growth are closely related (Levick et al., 2009; Sturtevant et al., 2009). The vegetation type influences the fire impact, whereas the fire impact largely determines the post-fire growth (van Langevelde et al., 2003; White et al., 2008). Knowledge of the spatio-temporal distribution of fire-vegetation impact is therefore essential to estimate the fire effects on ecological dynamics and to understand the fire-climate interactions. 


\subsection{Assessment of fire effects based on remote sensing}

Fire-vegetation interactions typically operate at broad temporal and spatial scales, that are unsuitable for field sampling. Therefore satellite imagery is often used to derive estimates of the spatio-temporal variability of firevegetation dynamics. One qualitative indicator used in this context is burn severity which quantifies the degree to which an ecosystem has changed owing to the fire and incorporates both short- and long-term post-fire effects, related to the direct fire impact and vegetation regrowth respectively (Lentile et al., 2006). Burn severity is defined as the absolute magnitude of environmental change caused by a fire (Morgan et al., 2001; Key and Benson, 2006).

Despite the wide use of satellite imagery for burn severity assessment and the current discussion on the temporal dimension in these assessments (Keeley, 2009), relatively few studies have addressed the influence of timing on the assessment of post-fire effects. Therefore, the aim of this paper is i) to illustrate the importance of the intra-annual fire-vegetation dynamics in comparison with inter-annual burn severity estimates, and ii) to illustrate the use coarse to moderate spatial resolution satellite data as a complementary alternative for monitoring these intra-annual fire-vegetation dynamics.

\subsubsection{Fire effects based on Landsat data}

Several studies have demonstrated the utility of the use of vegetation indices (VI) derived from Landsat imagery for mapping burn severity (for overview see French et al. (2008)). Most of this work was based on the correlation between burn severity mapped in the field and the normalized burn ratio (NBR) or bi-temporal differenced normalized burn ratio (dNBR) derived 
from Landsat imagery, leading to suggestions that NBR and dNBR maps derived from fine spatial resolution imagery provide a transferable means to measure burn severity in several ecosystem types (French et al., 2008). A major drawback of the Landsat based methodologies, however, is the dependency on image availability (Ju and Roy, 2008), which is limited due its temporal resolution (every 16 days) and cloud cover. This drawback is even more exaggerated in bi-temporal studies as they require image-to-image normalization (Coppin et al., 2004), including the removal of phenological, atmospheric and bi-directional reflectance function (BDRF) effects (Song, 2002; Verbyla et al., 2008; Veraverbeke et al., 2010e). As a result, dNBR analysis is practically limited to anniversary image acquisition dates to reduce shifts in the phenological state of the vegetation between data acquisition times. Consequently, NBR and dNBR maps are valuable for obtaining inter-annual information of burn severity over specific fires, but fail to provide a multitemporal overview of the intra-annual variability of fire-vegetation dynamics on regional to global scale (Michalek et al., 2000). Moreover, cloud-free multiple images from different years on anniversary dates are frequently not available (Song, 2002). Another consequence of these infrequent image acquisitions is the dependence of dNBR estimates on acquisition date. For example Key (2006) and Veraverbeke et al. (2010c) illustrated the importance of the time lag since the fire and seasonal timing of a Landsat acquisition on dNBR change and variability. This dNBR dependence on acquisition date inhibits the comparison of dNBR assessments between different fire dates and fire plots (Eidenshink et al., 2007; French et al., 2008; Verbyla et al., 2008). 
1.1.2. Fire effects based on coarse to moderate spatial resolution satellite data The use of coarse to moderate spatial resolution satellite data (e.g., SPOTVegetation (VGT), MODIS, etc.) has the potential of providing sound alternatives to NBR and dNBR estimates at the local scale, given their synoptic coverage and repeated temporal sampling. At these coarse spatial scales, time series can be analyzed that allow to assess the intra-annual fire-vegetation dynamics (Geerken, 2009) and the comparison between different fire dates. In this context, several time series have been proposed based on the evolution of post-fire VIs without any reference to the situation prior to the fire event (Fiorella and Ripple, 1993), the difference or ratio in VIs before and after the fire occurrence (White et al., 1996; Viedma et al., 1997; Henry and Hope, 1998; Kushla, 1998; Hicke et al., 2003) and the use of a regeneration index $(\mathrm{RI})$ that employs information of control plots located close to but unaffected by the fire, to correct for external influences and phenological variation (Díaz-Delgado et al., 1998; Díaz-Delgado and Pons, 2001; Riaño et al., 2002; Díaz-Delgado et al., 2003). The latter approach is founded on the assumption that the vegetation growth of the control plots can serve as an indicator of vegetation growth in case the fire had not occurred. As such, external influences (radiometric calibration uncertainty, errors in the atmospheric correction, bidirectional reflectance distribution function (BRDF) effects, topographic impact, and shifts in the phenological state of the vegetation between data acquisition) can be masked out and the variation in RI can be interpreted solely due to regeneration processes. Song (2002) highlighted the reduction of these kinds of image noise as the primary challenge when using multi-temporal imagery to monitor forest regrowth. Moreover, 
Viedma et al. (1997) and Song (2003) stressed the need for phenological and seasonal corrections to interpret long-term regrowth of the vegetation communities. A drawback of the RI approach, however, is its dependence of static reference data and inability to quantify heterogeneity within a fire plot. To overcome these limitations Lhermitte et al. (2010) proposed the control pixel regeneration index (pRI) that allows to quantify the vegetation regrowth for each fire pixel within a fire plot using selected control pixels based on time series similarity and spatial context. The pRI analysis provides a valuable alternative to study the intra-annual fire-vegetation dynamics.

\subsection{Paper overview}

In the framework of this paper, a savanna pilot study area was selected for its coexistence of woody and herbaceous vegetation, which reflect different intra- and inter-annual vegetation dynamics and vegetation greenness (Scanlon et al., 2002) where (i) green leaf cover of woody vegetation follows a weaker annual wave with low amplitude variations and (ii) green leaf cover of the herbaceous vegetation follows a strong annual phenological wave with high amplitude variations (Fuller et al., 1997; Scanlon et al., 2002). Consequently, differences in intra- and inter-annual fire-vegetation dynamics and vegetation greenness can be expected for the burn plots. To assess the importance of these intra- and inter-annual fire-vegetation dynamics in this paper, firstly the inter-annual fire-vegetation dynamics derived from Landsat and VGT imagery were analyzed. This allows to establish a baseline to compare both data sets. Secondly, metrics of intra-annual dynamics were derived from the VGT data using the control pixel based pRI approach and these metrics were contrasted with the inter-annual dynamics of both VGT and Landsat 
data.

\section{Data}

\subsection{Study area}

The pilot study area covered Landsat ETM+ scene 168/077 between 23$25^{\circ} \mathrm{S}$ and $30-32^{\circ} \mathrm{E}$ in the low-lying savanna of the northeastern part of South Africa and southern Mozambique (see Fig. 1). Elevations range from 260$839 \mathrm{~m}$ above sea level, and mean annual rainfall varies between $350 \mathrm{~mm}$ in the north and $750 \mathrm{~mm}$ in the south. The rainfall regime within the annual climatic season can be confined to the summer months (November to April), and over a longer period can be defined by extended wet and dry seasons. Most fires occur in the dry season, from approximately May to October, when herbaceous vegetation is either dead or dormant, and when deciduous trees have shed their leaves, thereby contributing to an accumulation of dry and fine fuels that are easily combustible.

The study area comprises mainly tropical grassland with scattered thorny, fine-leafed trees. In general, three dominant vegetation types are present in the fire affected area. In the west, the fire affected area on granite substrate shows a woody vegetation cover of $\pm 20 \%$ (red bushwillow (Combretum apiculatum), knobthorn (Acacia nigrescens), tamboti (Spirostachys africana) and marula (Sclerocarya birrea) (Eckhardt et al., 2000)). Here grasses accumulate during the growing season due a relatively low-grazing pressure. In the middle next to the Mozambican border, on basalt substrates, the woody cover is less $( \pm 5 \%)$ and grasses are more palatable and tend to be heavily grazed. Important tree species here include the knobthorn, leadwood (Combretum 
imberbe) and marula. In the eastern part of the study area (Mozambique), woody cover is much higher (up to 50\%). The distribution of tree cover is also visible in Fig. 1, that displays the fraction tree cover per pixel derived from MODIS vegetation continuous fields (VCF) for the year 2000. The VCF data were generated based on a regression tree algorithm from monthly composites of $500 \mathrm{~m}$ resolution MODIS data (Hansen et al., 2002, 2003).

\subsection{Burnt pixel data}

Fire scar data of the year 2000 were identified from the Globscar product (Simon et al., 2004) developed by the European Space Agency (ESA) using Along Track Scanning Radiometer (ATSR-2) daytime data of the year 2000. The product combines the result of two algorithms for burnt area detection: the $\mathrm{K} 1$ algorithm based on the geometrical characteristics of the burnt pixels in the NIR and thermal infrared (TIR) space, and the E1 algorithm derived from four different spectral channels (Simon et al., 2004). The final product is available with a $1 \mathrm{~km}$ spatial resolution at monthly intervals, but provides for each burnt pixel also the date of fire detection.

Additionally, burnt pixels were identified from the Global Burnt Area 2000 (GBA2000) initiative (Grégoire et al., 2003), not for analysis but to exclude errors in control pixel data. This approach was chosen since GBA2000 does not provide fire date and cannot be used for pRI calculations, but allows to exclude possible burnt pixels in the control pixel selection approach as it has higher estimates burnt area (Boschetti et al., 2004). 


\subsection{Control pixel data}

Control pixels were selected for input in the pRI approach proposed by Lhermitte et al. (2010). The pRI approach employs a pixel-based selection methodology to correct for external influences and phenological variation based on the Díaz-Delgado et al. (1998) logic. To obtain these control pixels that represent the temporal profile of the fire pixel in case the fire had not occurred, the pRI approach combines time series similarity and spatial context. The time series similarity condition allows to select control pixels with similar pre-fire vegetation characteristics as the burnt pixel, whereas the spatial context condition maximizes similar post-fire environmental conditions. Both these constraint allow the selection of control pixels that can be used to forecast the temporal behavior of each burned pixel if the fire would not have occurred.

In this study, the pRI procedure of Lhermitte et al. (2010) is followed to select control pixels from unburnt pixels in both the Globscar and GBA2000 data sets. The procedure uses the root mean square distance (RMSD) as time series similarity measure applied one year NDVI time series before the fire $\left(\mathrm{TSS}_{R M S D}\right)$ and four out of eight candidate control pixels as the spatial context constraint. Based on these constraints, each fire pixel is considered individually as seed pixel. Based on this seed pixel $p$, a first run is started that compares $p$ with its $N_{t}$ spatial adjacent pixels that did not burn (i.e., candidate control pixels). If $N_{t}<8$, the spatial neighborhood window around is gradually increased (e.g., from a 3 by 3 to a 5 by 5 window) until $N_{t} \geq 8$. Subsequently, the mean time series of the $x=4$ most similar candidate control pixels (based on $\operatorname{TSS}_{R M S D}$ ) are used to represent the vegetation 
growth of each burnt pixel in case the fire had not occurred without external influences such as phenology, atmospheric disturbances, etc. .

Fig. 2 shows the burnt pixels (reflected by their RMSD in the $\operatorname{TSS}_{R M S D}$ methodology in cyan-yellow-red), the selected control pixels (in green) and the original NBR image at $30 \mathrm{~m}$ resolution in October 2000 at the end of the fire season (in purple-dark blue). Comparison of the Globscar burnt pixels and the underlying NBR image, shows that the Globscar data effectively succeeded in detecting large burnt areas in the study area. It is also clearly visible that the amount of under-detection of burnt pixels is high, but that these undetected fire pixels are not selected as control pixels. These errors of under-detection, for example, can be seen on the north-western side where large fires are visible in the NBR image that are not detected by the Globscar project. However, as we focus in this paper on the variability in post-fire vegetation regrowth, the accurate amount of burnt pixels is not important and the study can be repeated as soon as better fire inventories become available.

\subsection{Satellite data}

\subsubsection{Fine spatial resolution}

Several studies have demonstrated the utility of spectral indices derived from Landsat imagery to quantify the fire-vegetation dynamics. Although a considerable amount of these studies focused on the use of the normalized difference vegetation index (NDVI), the normalized burn ratio (NBR) has become an operational spectral index for fire effects (for a comprehensive review of remote sensing techniques to assess wildfire severity using Landsat, see French et al. (2008)). The NBR relates to vegetation vigor and moisture 
by combining TM/ETM+ band 4 (NIR: 0.76-0.90 $\mu \mathrm{m})$ and band 7 (SWIR: 2.08-2.35 $\mu \mathrm{m})$ :

$$
\mathrm{NBR}=(\mathrm{NIR}-\mathrm{SWIR}) \backslash(\mathrm{NIR}+\mathrm{SWIR})
$$

In most cases, the NBR reliably separates burnt from unburnt surfaces, and optimally identifies a broad gradient of fire-effect levels within the burn. However, when using mono-temporal post-fire imagery, unburned sparsely vegetated areas and burned areas are often confounded (Key and Benson, 2005). Therefore, pre- and post-fire NBR images are generally bi-temporally differenced, resulting in the differenced NBR (dNBR), which permits a clear contrast between burned and unburned regions and correlates with burn severity mapped in the field, where exact definitions of burn severity vary but all relate to the degree of environmental change caused by fire (Roy et al., 2006).

In this research, the Landsat NBR data were selected as reference layers to describe the inter-annual fire-vegetation dynamics of the 2000 burn scars. The selection of the NBR was based on data availability, cloud cover and the necessity for anniversary image acquisition dates. As such two anniversary date images were selected (4 April 2000 and 28 April 2001) before the Landsat SLC failure (Pringle et al., 2009). Both scenes were geometrically corrected based on control points and a first order nearest neighbor algorithm. Subsequently, the images were atmospherically corrected and converted from digital numbers to reflectance values using the ATCOR2 algorithm developed by Richter (2006). Finally, the reflectance values were used to calculate NBR and dNBR by subtracting the 2001 and 2000 NBR images and the NBR an 
dNBR images were resampled to averaged NBR and dNBR values per $1 \mathrm{~km}^{2}$ for each Globscar burnt pixel.

\subsection{Coarse spatial resolution}

Time series of intra-annual fire-vegetation dynamics were constructed using NDVI time series derived from ten-daily NDVI image composites (S10) from the SPOT-VEGETATION (VGT) sensor over the study area. NDVI data derived from the red $(0.61-0.68 \mu \mathrm{m})$ and near infrared $(0.78-0.89 \mu \mathrm{m})$ bands were used since the NBR cannot be calculated due to the absence of the 2.08-2.35 $\mu \mathrm{m}$ band onboard of VGT. Preprocessing of the NDVI data was performed by the Vlaamse Instelling voor Technologisch Onderzoek (VITO, Mol, Belgium) in the framework of the Global Vegetation Monitoring (GLOVEG) preprocessing chain. It consisted of the Simplified Method for Atmospheric Correction (SMAC) (Rahman and Dedieu, 1994) and compositing of daily images at ten-day intervals based on the Maximum Value Compositing (MVC) criterion (Holben, 1986). The final NDVI data set consisted of ten-daily, 1 km resolution S10 composites for the period 1999-2004 with cloud affected pixels masked as missing data.

\section{Methodology}

To illustrate the importance of the intra-annual fire-vegetation dynamics in comparison with inter-annual burn severity estimates derived from Landsat imagery, (i) the inter-annual fire-vegetation dynamics of both Landsat and VGT images were contrasted to establish a inter-comparison baseline and (ii) metrics of intra-annual dynamics were derived from the VGT data using 
the pRI approach and these metrics were compared with the inter-annual dynamics of both VGT and Landsat data.

\subsection{Inter-annual fire-vegetation dynamics}

Two different approaches were applied to compare the inter-annual firevegetation dynamics of both Landsat and VGT data. Firstly, a comparison was performed between the bi-temporally differenced Landsat dNBR data and the bi-temporally differenced VGT NDVI values (dNDVI) of corresponding dates. Secondly, a comparison was established between the control pixel approach for both Landsat and VGT images for 28 April 2001. This was done by calculating the pRI:

$$
\mathrm{pRI}=\mathrm{VI}_{\text {burn }} / \overline{\mathrm{VI}}_{\text {control }}
$$

where $\mathrm{VI}_{\text {burn }}$ is the NBR and NDVI for burnt pixels of the Landsat and VGT data, respectively, and $\overline{\mathrm{VI}}_{\text {control }}$ is the mean NBR and NDVI for the selected control pixels of the Landsat and VGT data for each burnt pixel, respectively. Both approaches allow to assess the inter-annual fire-vegetation dynamics as they compare unburnt and burnt pixels, but the former approach is performed on a bi-temporal basis where external differences should be removed using anniversary dates, whereas the latter approach removes these differences using control pixels that reflect the vegetation growth in case the fire had not occurred. The combination of both approaches therefore allows to intercompare Landsat and VGT data, but also permits to assess the influence of external differences on the estimation of inter-annual firevegetation dynamics. 


\subsection{Intra-annual fire vegetation dynamics}

To assess the importance of intra-annual dynamics, an integrated change approach was used, represented by integrated metrics of intra-annual dynamics derived from the VGT data using pRI time series (pRI ${ }^{t}$; see Eq. 2) The integrated change was selected since it incorporates the combined effect of fire impact and recovery (Ricotta et al., 1999). This approach is relatively robust to noise in pRI time series as it removes random noise. The integral was calculated between the ideal post-fire time series $\mathrm{pRI}^{t}=1$ (when the fire did not occur) and the actual $\mathrm{pRI}^{t}$ time series:

$$
\mathrm{IpRI}=\sum_{t=t_{0}}^{t_{1}}\left(1-\mathrm{pRI}^{t}\right)
$$

where $t_{0}$ and $t_{1}$ define the integration starting and ending dates. These dates are defined as the moments when $\mathrm{pRI}^{t}=1$. For IpRI1 this implies that $t_{0}$ is the burning date and $t_{1}$ is the relative recovery date related to the number of post-fire observations before the $\mathrm{pRI}^{t}$ reaches one (i.e, when $\mathrm{pRI}^{t}=1$ for the first time in Fig. 3, which corresponds to the moment when $\left.\mathrm{VI}_{\text {burn }}=\overline{\mathrm{VI}}_{\text {control }}\right)$. For IpRI2, $t_{1}$ of pRI1 is used as $t_{0}$, whereas $t_{1}$ is derived from the subsequent moment when $\mathrm{pRI}^{t}$ reaches one (i.e, when $\mathrm{pRI}^{t}=1$ for the second time in Fig. 3). For the subsequent IpRIs, this procedure can be repeated as $t_{1}$ of the previous is as $t_{0}$, and $t_{1}$ is derived from the subsequent moment when $\mathrm{pRI}^{t}$ reaches one. In total, three metrics (IpRI1, IpRI2 and IpRI3) were calculated and the selection of $t_{0}$ and $t_{1}$ was limited to one year after fire to avoid incorporating fire pixels of the 2001 fire season.

The computation of $t_{0}$ and $t_{1}$, based on the moments when $\mathrm{pRI}^{t}$ equals 
one, is crucial in the calculation of IpRI values. Therefore, a smoothed pRI curve based on a cubic spline with two knots per year was used to remove outlier values in the estimation of $t_{0}$ and $t_{1}$. The cubic spline is based on piecewise polynomial functions (between the knots) that are designed to minimize a weighted combination of the average squared approximation error over observed data (Harrell, 2001). As a result, the smoothed curve provides an approximation of the original $\mathrm{pRI}^{t}$ time series that is more robust to outlier values and that can be used to calculate $t_{0}$ and $t_{1}$ with higher accuracy.

The calculation of the IpRIs is illustrated in Fig. 3, where the dot-dash line represents the cubic spline fitted on the post-fire $\mathrm{pRI}^{t}$ time series. When the cubic spline reaches one, the moments $t_{0}$ and $t_{1}$ (represented by the dashed lines) are derived and the three IpRI estimates are calculated based on Eq. 3 from the shaded area using the original $\mathrm{pRI}^{t}$ values. As such, the IpRI provides a measures of combined changes due to the fire event.

IpRI1 estimates will show large positive values for high fire-vegetation impact. This can be attributed to the large decrease over time in VIs after fire occurrence (Pereira, 2003; Silva et al., 2003), resulting in pRI ${ }^{t}$ below one and positive IpRI1 values in Eq. 3. Positive IpRI1 values close to zero, on the other hand, will be associated with pixels that show only a small fire impact or contain a very fast recovery, whereas negative values will originate from pixels that are falsely detected or recover before the fire is detected, resulting in $\mathrm{pRI}^{t}$ above one and negative IpRI1 values in Eq. 3. IpRI2 values, on the other hand, will show large negative values when the post-fire pRI reflects an increased vegetation greenness some time after the fire impact due to the nutrient availability, whereas IpRI3 values will show large positive 
values when the $\mathrm{pRI}^{t}$ drops again after a short period of increased vegetation greenness.

\section{Results}

\subsection{Inter-annual fire-vegetation dynamics}

Fig. 4 illustrates the comparison of the bi-temporal estimates of firevegetation impact by Landsat dNBR and VGT dNDVI data. Fig. 4a shows the bi-temporal Landsat dNBR data represented by averaged dNBR values per $1 \mathrm{~km}^{2}$ for the Globscar burnt pixels, whereas Fig. 4b shows the bi-temporal VGT dNDVI data for the same burnt pixels. In both figures, yellow-red colors indicate positive values, associated with decreased NBR and NDVI values one year after the fire. Cyan-blue colors, on the other hand, reflect negative dNBR and dNDVI values, indicating a higher NBR or NDVI values one year after the fire. Comparison of both figures shows that, although local differences occur, dNBR and dNDVI detect broadly identical spatial patterns when comparing unburnt and burnt pixels. For example, it is clear that both data sets reflect positive dNBR and dNDVI values and high fire-vegetation impact for points 1-3, whereas they show very low or even negative dNBR and dNDVI values for points 4-5. This is also clear when performing a linear regression analysis between Landsat dNBR and VGT dNDVI (not shown), which indicates a statistically significant linear relationship $(p=0.01)$ with a $\mathrm{R}^{2}=0.39$.

Fig. 5 reflects the comparison of the control pixel estimates of firevegetation impact of Landsat NBR and VGT NDVI data, where Fig. 5a-b show the control pixel based pRI of Landsat NBR and VGT NDVI, 
respectively. Here, yellow-red colors indicate negative values, associated with decreased NBR and NDVI values in comparison with the unburnt control pixels. Cyan-blue colors, on the other hand, reflect positive dNBR and dNDVI values, indicating a higher NBR or NDVI values for the burnt than for the unburnt control pixels. Again it is clear that both pRI of NBR and NDVI reflect broadly identical spatial patterns, although the maps are more speckled and less smooth than for dNBR and dNDVI. This is also apparent when performing a linear regression analysis between Landsat pNBR and VGT pNDVI data (not shown), which again indicates a statistically significant linear relationship $(p=0.01)$ but with a lower $\mathrm{R}^{2}=0.10$.

Although Figs. 4-5 demonstrate agreement between Landsat NBR and VGT NDVI data, comparison of the spatial patterns between both figures reveals the differences in fire-vegetation impact when using either a bi-temporal approach or a control pixel approach. For example, its is clear that several points which show a high fire-vegetation impact in the bi-temporal approach (e.g., points 2), show a less pronounced fire-vegetation impact when determined by the control pixel approach. This difference illustrates the importance of external differences on the estimation of inter-annual fire-vegetation dynamics. This is also clear from Fig. 6, which shows the difference in mean VGT NDVI (dNDVI) for the 1999-2000 and 2000-2001 November to April growing seasons for both burnt and control pixels. This difference in mean NDVI can be considered an indicator of the phenological difference in total greenness of vegetation between growing seasons (Defries et al., 1995). This difference in total greenness between growing seasons indicates that the spatial patterns of increased and decreased greenness equally affect the fire 
and control pixels. Moreover, contrasting of Figs. 4 and 6 reveals that the spatial patterns of increased-decreased greenness between growing seasons affects the bi-temporal fire-vegetation approach, as areas of increased greenness show a smaller fire-vegetation dNBR-dNDVI impact than areas with a decreased greenness. However, as this difference in increased-decreased greenness is similar for the corresponding control pixels, it is evident that the bi-temporal approach does not properly account for changes in phenology between years.

\subsection{Intra-annual fire vegetation dynamics}

Figs. 7 show the three IpRI metrics derived from the VGT NDVI pRI ${ }^{t}$ time series, where Fig. 7a reflects the initial fire-vegetation impact (IpRI1), Fig. 7b illustrates the increased vegetation greenness some time after the fire (IpRI2), and Fig. 7c shows the subsequent pRI ${ }^{t}$ drop after a short period of increased vegetation greenness. Comparison of these derived metrics reflects the importance the intra-annual dynamics, as many pixels show large positive IpRI1 values, indicating a severe NDVI decrease after fire, but also large negative IpRI2 values, indicating increased vegetation greenness some time after the fire, followed again by large positive IpRI3 values, indicating a new NDVI decrease after the growing season. This is also clear when looking at the pRI ${ }^{t}$ time series in Figs. 8 of the example points highlighted in Figs. 7. These example points were selected randomly to represent different temporal patterns of fire-vegetation. From Figs. 7 different temporal patterns of fire-vegetation impact can be derived, that show pronounced intra-annual regrowth dynamics. For example, point 1 shows a large fire-vegetation impact, showing large positive IpRI1 values where both $\mathrm{pRI}^{t}$ time series don't reach 
the pre-fire level of $\mathrm{pRI}^{t}=1$ and thus IpRI $2=\mathrm{IpRI} 3=0$. Point 2 , on the other hand, shows a large fire-vegetation impact but reaches $\mathrm{pRI}^{t}=1$ within one year after the fire, but doesn't show a decrease afterwards, whereas point 3 reaches $\mathrm{pRI}^{t}=1$ rapidly, followed by a period of increased vegetation greenness and a subsequent drop below $\mathrm{pRI}^{t}=1$ at the end of the growing season. This drop does not occur for point 4 that shows a large period of increased vegetation greenness after a short fire impact. Point 5 finally shows less pronounced intra-annual dynamics, as its variability reaches $\mathrm{pRI}^{t}=1$ after some time and then show little deviation from $\mathrm{pRI}^{t}=1$.

Moreover, Figs. 8 illustrate the moments of the April 2000 and 2001 Landsat image acquisition, represented by a small triangle. Since these acquisition dates coincide with the end of the growing season, the importance of the annual phenological variations related to the growing season can be inferred. For most points, for example, this annual phenological cycle within the $\mathrm{pRI}^{t}$ time series is clearly apparent as it shows different, often higher pRI values during the growing season and than at the end of the growing season. These increased values pRI values during the growing season can also be related to the amount of tree-grass cover (Fig. 1), since all these points typically occur in regions with relative high grass abundance and lower tree fractions.

\section{Discussion}

\subsection{Comparison of inter- and intra-annual fire vegetation dynamics} The comparison of inter-annual fire-vegetation dynamics of both Landsat and VGT data illustrates two major topics often discussed in literature. Firstly, it demonstrates the similarity of spatial patterns between NBR and 
NDVI data, although the correlation at pixel level is low. This similarity of spatial patterns with differences at the pixel level can also be observed in the study of Fox et al. (2008), who compared dNDVI and dNBR values in a heterogeneous forest-scrubland-vineyard environment. These low correlations at pixel level could be explained when i) looking at the study of Veraverbeke et al. (2010a,c) who already established moderate $\mathrm{R}^{2}$ values due to sensor and scale differences when focusing only on dNBR data, and ii) the expected decrease in $\mathrm{R}^{2}$ when dNBR data are compared to a different index such as dNVDI. The lower $\mathrm{R}^{2}$ for $\mathrm{pNBR}$ and pNDVI values can moreover be justified by the wider probability distribution function when studying a ratio based index (e.g., pNBR and pNDVI) in comparison with a difference based index (e.g., dNBR and dNDVI) (Marsaglia, 1965). Although this low correlations at pixel level indicate that NBR and NDVI cannot be used interchangeably due to high variations at pixel level, the similarity in spatial patterns suggests that the use of the NDVI index at coarse to moderate spatial resolution may provide a valuable alternative for NBR, when the 2.08-2.35 $\mu \mathrm{m}$ wavelength is not available. This was also established by Epting et al. (2005), Escuin et al. (2008), Hoy et al. (2008), Veraverbeke et al. (2010b), and Veraverbeke et al. (2010d) who determined the dNBR as the optimal index to assess wildfire impact based on field measurements, but also found high correlations for dNDVI. Epting et al. (2005) studied the efficiency of single date imagery to determine the wildfire impact and again the NBR outperformed NDVI, but also high correlations for NDVI were obtained. Nevertheless, when fire specific wavelengths are available at coarse to moderate spatial resolution (e.g., MODIS) the use of fire adapted vegetation indices, such as NBR, may 
provide a better alternative, since NDVI time series never were designed to capture specific vegetation variation after fire (Lasaponara, 2006).

Secondly, the comparison of inter-annual fire-vegetation dynamics indicates the importance of the elimination of external influences (e.g., plant phenology) when using multi-temporal Landsat imagery, stressed by Song (2003), Schroeder et al. (2006), Vicente-Serrano et al. (2008), and Verbyla et al. (2008). In this context, the use of the higher temporal frequency of imagery, (e.g., coarse to moderate resolution imagery such as VGT or MODIS data (Veraverbeke et al., 2010c)) can be a vital complement to traditional Landsat dNBR analysis. Although these coarser data sets fail to express small scale spatial heterogeneity available in Landsat imagery (Key, 2006) and are complex to analyze at the sub-pixel scale (Eckmann et al., 2008) when fires affect vegetation differently within a coarse pixel, they can serve as complementary data to analyze the temporal dimension and provide an alternative for the assessment of burn severity at continental to global scales (e.g., Verbesselt et al. (2010)). When using coarse to moderate spatial resolution data, the control plot approach proposed by Díaz-Delgado et al. (1998) and adapted by Lhermitte et al. (2010) may provide a valuable alternative to represent vegetation regrowth into one index $\mathrm{pRI}^{t}$ that expresses the variation due to regeneration processes without external influences. Bi-temporal assessments can only partly contribute to this interpretation of burn severity as they fail to include intra-annual post-fire vegetation responses.

\subsection{Consequences for bi-temporal assessments}

The failure of including these intra-annual post-fire vegetation responses in bi-temporal assessments is clearly apparent when looking at the intra- 
annual fire-vegetation dynamics represented in Figs. 7-8, where annual and other regeneration processes can be observed. Due to this intra-annual variability, the timing of Landsat image acquisition will greatly influence the derived Landsat measures. This is evident, when looking at the moment of Landsat acquisition in Fig. 8, where the moment of the April 2000 and 2001 image acquisition are represented by a small triangle. In this figure, small changes in acquisition dates will lead to different conclusions on post-fire vegetation interaction due to two main effects. Firstly, fire-induced change decreases with vegetation recovery (Allen and Sorbel, 2008; Veraverbeke et al., 2010c), especially in quickly recovering ecotypes such as savanna. Allen and Sorbel (2008), for example, established large differences due to fast recovery when the image acquisition timing differed in bi-temporal burn severity assessments. Secondly, the seasonal timing determines the vegetation productivity and wetness of both the control and burned plots which influences the annual phenological cycle and affects the absolute magnitude of change in any bi-temporal data set (Key and Benson, 2006; Veraverbeke et al., 2010c). Verbyla et al. (2008), on the other hand, reported large differences in dNBR values due to a combined seasonality effect of senescing vegetation and changing illumination conditions.

The senescing effect in combination with tree-grass interaction plays a crucial role in our study area, as can be seen by looking at the annual phenological cycle within the $\mathrm{pRI}^{t}$ time series for the pixel that show low tree fractions in Fig. 1. The importance of this annual phenological cycle was stressed by Fuller et al. (1997), Scanlon et al. (2002), and Lu et al. (2003) who suggested that in savanna ecosystems the grass layer dominates annual 
cycle of the NDVI signal throughout most of the seasonal cycle, and that only during the senescent dry season the contribution of the tree is relatively more important. This difference can be explained by looking at the strategies for water use, where grasses are considered to be intensive exploiters while trees and shrubs are extensive exploiters (Burgess, 1995). As such, trees, which have root systems that penetrate both the shallow and deeper soil layers, have a more persistent supply of soil water than grasses, which have dense, shallow root systems and depend on water that is ephemerally available in the upper layer of the soil. Relative to trees, grasses exhibit a greater areal expansion of biomass in response to rainfall in savanna ecosystems, whereas short-term greening of trees is restricted by the standing woody biomass. All these factors contribute to greater expected VI response to precipitation by grasses than by trees (Lu et al., 2003). The effects of annual phenological cycle and fast recovery have however severe implications for the use of the regeneration indices in mixed ecosystems with herbaceous cover. For example, pRI observations at certain moment in the growing season tend to indicate a complete vegetation recovery or even increased greenness, whereas this is not necessarily true for the woody vegetation component. All together, these effects limit any comparison of two bi-temporal fire-vegetation impact assessments and link closely to the recent confusion in post-fire effects terminology (fire severity, burn severity, ecosystem response, etc.) (Keeley, 2009).

One of the main interests of estimating the spatio-temporal variability of fire-vegetation dynamics is the categorization of the fire-affected pixels in severity classes (Epting et al., 2005; Key and Benson, 2005). This classification is however not straightforward due to the difficulty to compare dNBR 
assessments between different fire dates and ecosystems (Eidenshink et al., 2007; Lentile et al., 2007; Miller and Thode, 2007). Miller and Thode (2007) proposed a relative version of the dNBR that allows the comparison among different land cover types, especially in heterogeneous landscapes. This approach does not handle timing differences which may be present among different assessments. Consequently, the absolute values of bi-temporal dNBR maps are highly dependent on the timing of the assessment and caution is advised when using the bi-temporal values to monitor and compare trends in fire-vegetation impact in time or across regions. The use of $\mathrm{pRI}^{t}$ time series, however, shows to have potential as a input parameter to spatio-temporally compare trends in fire-vegetation impact.

In this study, we proposed a metric IpRI that integrates this temporal variability. This approach was selected to average individual errors over time and remove random noise (the expected integral of random noise is zero). IpRI estimates are therefore robust random noise and are moreover relatively independent to small errors in the determination of $t_{0}$ and $t_{1}$. This can be explained by the fact the $\mathrm{pRI}^{t}$ values at the end of the recovery only minimally contribute to the total IpRI. This integrative approach is as such a first step to a spatio-temporal approach to assess severity, which can also be applied on different data sets (e.g., Veraverbeke et al. (2010a)), but it should also be tested and refined in different ecosystems with other environmental and fire characteristics where, for example, a vegetation greenness increase some time after the fire impact followed by a new greenness drop after a short period are not expected. Therefore, interpretation of IpRI signals in these ecosystems will be different, but the integration of temporal variability 
can still provide a valuable approach due to its robustness to noise.

\section{Conclusion}

Wildfires play an essential role in several ecological processes and affect the vegetation regrowth at a variety of spatial and temporal scales. Several studies have investigated the potential of satellite imagery to quantify the spatio-temporal fire-vegetation impact over large areas. Most studies however depend on Landsat image availability, for which image acquisition dates are limited, resulting in a reduced capacity to capture the intra-annual firevegetation dynamics and the difficulty to compare different fire plots and dates. The objective of this paper was to illustrate the importance of the intra-annual fire-vegetation dynamics in comparison with inter-annual burn severity estimates derived from Landsat imagery. In this context, a savanna pilot study area was selected based on its combination of woody and herbaceous vegetation, which show different intra- and inter-annual vegetation dynamics and vegetation greenness.

Four main conclusions can be derived from this analysis on intra-annual fire-vegetation dynamics based on the comparison of Landsat NBR and VGT NDVI data:

- It demonstrated the similarity in spatial patterns when using NBR and NDVI data in both a bi-temporal and control pixel approach.

- It revealed the importance of the elimination of external influences (e.g., phenological variations) when using bi-temporal Landsat imagery. This confirmed the importance of the control pixel approach (pRI) which 
provides a valuable alternative to represent vegetation regrowth into one index $\mathrm{pRI}^{t}$ that without the effect of external influences.

- The use of the pRI and the integrated metric IpRI confirmed the failure of including intra-annual post-fire vegetation responses in bi-temporal assessments, especially in quickly recovering ecotypes such as savanna where the grass layer dominates the annual NDVI cycle throughout most of the season.

- It illustrated the potential of $\mathrm{pRI}^{t}$ time series to operate as a input parameter to spatio-temporally compare trends in fire-vegetation impact.

\section{Acknowledgements}

This work was performed in the framework of a research project on satellite remote sensing of terrestrial ecosystem dynamics, funded by the Belgian Science Policy Office (GLOVEG-VG/00/01; GLOVEX-SR/16/81; ECOSEGSR/01/108). The SPOT VGT S10 data set was generated by the Vlaamse Instelling voor Technologisch Onderzoek (VITO). We are indebted to the editor and reviewers for their detailed comments that led to an improved version of the manuscript.

\section{References}

Allen, J. L., Sorbel, B., 2008. Assessing the differenced Normalized Burn Ratio's ability to map burn severity in the boreal forest and tundra ecosystems of Alaska's national parks. International Journal of Wildland Fire 17, $463-475$. 
Boschetti, L., Eva, H. D., Brivio, P. A., Gregoire, J. M., 2004. Lessons to be learned from the comparison of three satellite-derived biomass burning products 31, L21501.

Burgess, T. L., 1995. The desert grassland. The University of Arizona Press, Tucson, AZ, Ch. Dessert grassland, mixed shrub savanna, shrub steppe, or semidesert scrub? The dilemma of coexisting growth forms., pp. 31-67.

Coppin, P., Jonckheere, I., Lambin, E., Nackaerts, K., Muys, B., 2004. Digital change detection methods in ecosystem monitoring: a review. International Journal of Remote Sensing 25, 1565-1596.

Defries, R. S., Hansen, M. C., Townshend, J. R. G., 1995. Global discrimination of land cover types from metrics derived from AVHRR pathfinder data. Remote Sensing of Environment 54, 209-222.

Díaz-Delgado, R., Lloret, F., Pons, X., 2003. Influence of fire severity on plant regeneration by means of remote sensing imagery. International Journal of Remote Sensing 24 (8), 1751-1763.

Díaz-Delgado, R., Pons, X., 2001. Spatial patterns of forest fires in Catalonia NE of Spain along the period 1975-1995 - Analysis of vegetation recovery after fire. Forest Ecology and Management 147 (1), 67-74.

Díaz-Delgado, R., Salvador, R., Pons, X., 1998. Fire management and landscape ecology. International Association of Wildland Fire, Fairfield, WA, USA, Ch. Monitoring of plant community regeneration after fire by remote sensing, pp. 315-324. 
Eckhardt, H. C., van Wilgen, B. W., Biggs, H. C., 2000. Trends in woody vegetation cover in the Kruger National Park, South Africa, between 1940 and 1998. African Journal of Ecology 38, 108-115.

Eckmann, T. C., Roberts, D. A., Still, C. J., 2008. Using multiple endmember spectral mixture analysis to retrieve subpixel fire properties from MODIS. Remote Sensing of Environment 112 (10), 3773-3783.

Ehrlich, D., Lambin, E. F., Malingreau, J. P., 1997. Biomass burning and broad-scale land-cover changes in Western Africa. Remote Sensing of Environment 61 (2), 201-209.

Eidenshink, J., Schwind, B., Brewer, K., Zhu, Z., Quayle, B., Howard, S., 2007. A project for monitoring trends in burn severity. Fire Ecology 3, $3-21$.

Epting, J., Verbyla, D., Sorbel, B., 2005. Evaluation of remotely sensed indices for assessing burn severity in interior Alaska using Landsat TM and ETM+. Remote Sensing of Environment 96, 328-339.

Escuin, S., Navarro, R., Fernandez, P., 2008. Fire severity assessment by using NBR (Normalized Burn Ratio) and NDVI (Normalized Difference Vegetation Index) derived from LANDSAT TM/ETM images. International Journal of Remote Sensing 29 (4), 1053-1073.

Eva, H., Lambin, E. F., 2000. Fires and land-cover change in the tropics: a remote sensing analysis at the landscape scale. Journal of Biogeography $27(3), 765-776$. 
Fiorella, M., Ripple, W. J., 1993. Analysis of conifer forest regeneration using Landsat Thematic Mapper. Photogrammetric Engineering and Remote Sensing 59 (9), 1383-1388.

Fox, D., Maselli, F., Carrega, P., 2008. Using spot images and field sampling to map burn severity and vegetation factors affecting post forest fire erosion risk. CATENA 75 (3), 326-335.

French, N. H. F., Kasischke, E. S., Hall, R. J., Murphy, K. A., Verbyla, D. L., Hoy, E. E., Allen, J. L., 2008. Using Landsat data to assess fire and burn severity in the North American boreal forest region: An overview and summary of results. International Journal of Wildland Fire 17 (4), $443-462$.

Fuller, D. O., Prince, S. D., Astle, W. L., 1997. The influence of canopy strata on remotely sensed observations of savanna-woodlands. International Journal of Remote Sensing 18 (14), 2985-3009.

Geerken, R., 2009. An algorithm to classify and monitor seasonal variations in vegetation phenologies and their inter-annual change. ISPRS Journal of Photogrammetry \& Remote Sensing 64 (4), 422-431.

Grégoire, J. M., Tansey, K., Silva, J. M. N., 2003. The GBA2000 initiative: developing a global burnt area database from SPOT-VEGETATION imagery. International Journal of Remote Sensing 24 (6), 1369-1376.

Hansen, M. C., DeFries, R. S., Townshend, J. R. G., Carroll, M., Dimiceli, C., Sohlberg, R. A., 2003. Global percent tree cover at a spatial resolution 
of 500 meters: first results of the MODIS vegetation continuous fields algorithm. Ecological Interactions 7, 1-15.

Hansen, M. C., DeFries, R. S., Townshend, J. R. G., Marufud, L., Sohlberg, R. A., 2002. Development of a MODIS tree cover validation data set for Western Province, Zambia. Remote Sensing of Environment 83, 320-335.

Harrell, F. E., 2001. Regression modeling strategies: with applications to linear models, logistic regression and survival analysis. Springer-Verlag, New-York, USA.

Henry, M. C., Hope, A. S., 1998. Monitoring post-burn recovery of chaparral vegetation in southern California using multi-temporal satellite data. International Journal of Remote Sensing 19 (16), 3097-3107.

Hicke, J. A., Asner, G. P., Kasischke, E. S., French, N. H. F., Randerson, J. T., Collatz, G. J., Stocks, B. J., Tucker, C. J., Los, S. O., Field, C. B., 2003. Postfire response of North American boreal forest net primary productivity analyzed with satellite observations. Global Change Biology 9 (8), 1145-1157.

Hoelzemann, J. J., Schultz, M. G., Brasseur, G. P., Granier, C., Simon, M., 2004. Global Wildland Fire Emmission Model (GWEM): evaluating the use of global area burnt satellite data. Journal of Geophysical Research 109 (D14S04), doi:10.1029/2003JD003666.

Holben, B. N., 1986. Characterization of maximum value composites from temporal AVHRR data. International Journal of Remote Sensing 7, 14171434. 
Hoy, E. E., French, N. H. F., Turetsky, M. R., Trigg, S. N., Kasischke, E. S., 2008. Evaluating the potential of Landsat TM/ETM+ imagery for assessing fire severity in Alaskan black spruce forests. International Journal of Remote Sensing 17 (4), 500-514.

Ju, J., Roy, D., 2008. The availability of cloud-free Landsat ETM+ data over the conterminous United States and globally. Remote Sensing of Environment 112, 1196-1211.

Keeley, J. E., 2009. Fire intensity, fire severity and burn severity: a brief review and suggested usage. International Journal of Wildland Fire 18, 116-126.

Key, C., Benson, N., 2005. FIREMON: Fire effects monitoring and inventory system. USDA Forest Service, Rocky Mountains Research Station, general technical report rmrs-gtr-164-cd la Landscape assessment: ground measure of severity; the Composite Burn Index, and remote sensing of severity, the Normalized Burn Index, pp. 1-51.

Key, C. H., 2006. Ecological and sampling constraints on defining landscape fire severity. Fire Ecology 2 (2), 34-59.

Key, C. H., Benson, N. C., 2006. FIREMON - Landscape assessment documents. Tech. Rep. RMRS-GTR-164, United States Department of Agriculture, Forest Service.

Kokaly, R. F., Rockwell, B. W., Haire, S. L., King, T. V., 2007. Characterization of post-fire surface cover, soils, and bum severity at the Cerro 
Grande Fire, New Mexico, using hyperspectral and multispectral remote sensing. Remote Sensing of Environment 106, 305-325.

Kushla, J. D., 1998. Assessing wildfire effects with Landsat thematic mapper data. International Journal of Remote Sensing 19 (13), 2493-2507.

Lasaponara, R., 2006. Estimating spectral separability of satellite derived parameters for burned areas mapping in the Calabria region by using SPOTVegetation data. Ecological Modelling 196 (1-2), 265-270.

Lentile, L., Morgan, P., Hudak, A., Bobbitt, M., Lewis, S., Smith, A., Robichaud, P., 2007. Post-fire burn severity and vegetation response following eight large wildfires across the western United States. Fire Ecology 3, 91108.

Lentile, L. B., Holden, Z. A., Smith, A. M. S., Falkowski, M. J., Hudak, A. T., Morgan, P., Lewis, S. A., Gessler, P. E., Benson, N. C., 2006. Remote sensing techniques to assess active fire characteristics and postfire effects. International Journal of Wildland Fire 15, 319-345.

Levick, S. R., Asner, G. P., Kennedy-Bowdoin, T., Knapp, D. E., 2009. The relative influence of fire and herbivory on savanna three-dimensional vegetation structure. Biological Conservation 142, 1693-1700.

Lhermitte, S., Verbesselt, J., Verstraeten, W. W., Coppin, P., 2010. A pixel based regeneration index using time series similarity and spatial context. Photogrammetric Engineering and Remote Sensing 76 (6), 673-682.

Lu, H., Raupach, M. R., McVicar, T. R., Barrett, D. J., 2003. Decomposition 
of vegetation cover into woody and herbaceous components using AVHRR NDVI time series. Remote Sensing of Environment 86, 1-18.

Marsaglia, G., 1965. Ratios of normal variables and ratios of sums of uniform variables. Journal of the American Statistical Association 60 (309), 193204.

Michalek, J. L., French, N. H. F., Kasischke, E. S., Johnson, R. D., Colwell, J. E., 2000. Using Landsat TM data to estimate carbon release from burned biomass in an Alaskan spruce forest complex. International Journal of Remote Sensing 21 (2), 323-338.

Miller, J. D., Thode, A. E., 2007. Quantifying burn severity in a heterogeneous landscape with a relative version of the delta Normalized Burn Ratio (dNBR). Remote Sensing of Environment 109, 66-80.

Morgan, P., Hardy, C. C., Swetnam, T., G., R. M., G., L. L., 2001. Mapping fire regimes across time and space: Understanding coarse and fine-scale fire patterns. International Journal of Wildland Fire 10, 329-342.

Nepstad, D. C., Verssimo, A., Alencar, A., Nobre, C., Lima, E., Lefebvre, P., Schlesinger, P., Potter, C., Moutinho, P., Mendoza, E., Cochrane, M., Brooks, V., 1999. Large-scale impoverishment of Amazonian forests by logging and fire. Nature 398 (6727), 505-508.

Pereira, J. M. C., 2003. Remote sensing of burned areas in tropical savannas. International Journal of Wildland Fire 12, 259-270.

Pringle, M. J., Schmidt, M., Muir, J. S., 2009. Geostatistical interpolation 
of SLC-off Landsat ETM+ images. ISPRS Journal of Photogrammetry \& Remote Sensing 64 (6), 654-664.

Rahman, H., Dedieu, G., 1994. SMAC: A simplified method for the atmospheric correction of satellite measurements in the solar spectrum. International Journal of Remote Sensing 15, 123-143.

Reilly, M. J., Wimberly, M. C., Newell, C. L., 2006. Wildfire effects on plant species richness at multiple spatial scales in forest communities of the southern Appalachians. Journal of Vegetation Science 94, 118-130.

Riaño, D., Chuvieco, E., Ustin, S., Zomer, R., Dennison, P., Roberts, D., Salas, J., 2002. Assessment of vegetation regeneration after fire through multitemporal analysis of AVIRIS images in the Santa Monica Mountains. Remote Sensing of Environment 79 (1), 60-71.

Richter, R., 2006. Atmospheric / topographic correction for satellite imagery. Tech. Rep. DLR-IB 565-01/05, DLR, Wessling, Germany.

Ricotta, C., Avena, G., De Palma, A., 1999. Mapping and monitoring net primary productivity with AVHRR NDVI time-series: statistical equivalence of cumulative vegetation indices. ISPRS Journal of Photogrammetry \& Remote Sensing 54 (4-5), 325-331.

Roy, D. P., Boschetti, L., Trigg, S. N., 2006. Remote sensing of fire severity: Assessing the performance of the normalized burn ratio. IEEE Geoscience and Remote Sensing Letters 3, 112-116.

Running, S. W., 2008. Ecosystem disturbance, carbon, and climate. Science 321 (5889), 652-653. 
Scanlon, T. M., Albertson, J. D., Caylor, K. K., Williams, C. A., 2002. Determining land surface fractional cover from NDVI and rainfall time series for a savanna ecosystem. Remote Sensing of Environment 82, 376388.

Schroeder, T. A., Cohen, W. B., Song, C., Canty, M. J., Yang, Z., 2006. Radiometric correction of multi-temporal Landsat data for characterization of early successional forest patterns in western Oregon. Remote Sensing of Environment 103, 16-26.

Silva, J. M. N., Pereira, J. M., Cabral, A., Sá, A. C. L., Vasconcelos, M. J. P., Mota, B., Grégoire, J.-M., 2003. An estimate of the area burned in southern Africa during the 2000 dry season using SPOTVEGETATION satellite data. Journal of Geophysical Research 108 (D13), doi.10.1029/2002JD002320.

Simon, M., Plummer, S., Fierens, F., Hoelzemann, J. J., Arino, O., 2004. Burnt area detection at global scale using ATSR-2: the GLOBSCAR products and their qualification. Journal of Geophysical Research 109 (D14S02), doi:10.1029/2003JD003622.

Song, C. H., 2002. The spectral/temporal manifestation of forest succession in optical imagery - The potential of multitemporal imagery. Remote Sensing of Environment 82 (2-3), 285-302.

Song, C. H., 2003. Monitoring forest succession with multitemporal Landsat images: Factors of uncertainty. IEEE Transactions on Geoscience and Remote Sensing 41 (11), 2557-2567. 
Sturtevant, B. R., Scheller, R. M., Miranda, B. R., 2009. Simulating dynamic and mixed-severity fire regimes: A process-based fire extension for LANDIS-II. Ecological Modelling 220, 3380-3393.

Van Der Werf, G. R., Randerson, J. T., Collatz, J., Giglio, L., 2003. Carbon emission from fires in tropical and subtropical ecosystems. Global Change Biology 9, 547-562.

van Langevelde, F., van de Vijver, Claudius A. D. M., K. L., van de Koppel, J., de Ridder, N., van Andel, J., Skidmore, A. K., Hearne, J. W., Stroosnijder, L., Bond, W. J., Prins, H. H. T., Rietkerk, M., 2003. Effects of fire and herbivory on the stability of savanna ecosystems. Ecogoly 84 (2), $337-350$.

Veraverbeke, S., Lhermitte, S., Verstraeten, W. W., Goossens, R., 2010a. A time-integrated MODIS burn severity assessment using the multi-temporal differenced Normalized Burn Ratio (dNBRMT). International Journal of Applied Earth Observation and Geoinformation, In Press.

Veraverbeke, S., Lhermitte, S., Verstraeten, W. W., Goossens, R., 2010b. Evaluation of pre/post-fire differenced spectral indices for assessing burn severity in a Mediterranean environment with Landsat Thematic Mapper. International Journal of Remote Sensing In press.

Veraverbeke, S., Lhermitte, S., Verstraeten, W. W., Goossens, R., 2010c. The temporal dimension of differenced Normalized Burn Ratio (dNBR) fire/burn severity studies: the case of the large 2007 Peloponnese wildfires in Greece. Remote Sensing of Environment, In Press. 
Veraverbeke, S., Verstraeten, W. W., Lhermitte, S., Goossens, R., 2010d. Evaluating Landsat Thematic Mapper spectral indices for estimating burn severity of the 2007 Peloponnese wildfires in Greece. International Journal of Wildland Fire In press.

Veraverbeke, S., Verstraeten, W. W., Lhermitte, S., Goossens, R., 2010e. Illumination effects on the differenced Normalized Burn Ratio's optimality for assessing fire severity. International Journal of Applied Earth Observation and Geoinformation 12, 60-70.

Verbesselt, J., Hyndman, R., Newnham, G., Culvenor, D., 2010. Detecting trend and seasonal changes in satellite image time series. Remote Sensing of Environment 114, 106-115.

Verbyla, D., Kasischke, E., Hoy, E., 2008. Seasonal and topographic effects on estimating fire severity from Landsat TM/ETM+ data. International Journal of Wildland Fire 17, 527-534.

Vicente-Serrano, S. M., Perez-Cabello, F., Lasanta, T., Oct. 2008. Assessment of radiometric correction techniques in analyzing vegetation variability and change using time series of Landsat images. Remote Sensing of Environment 112 (10), 3916-3934.

Viedma, O., 2008. The influence of topography and fire in controlling landscape composition and structure in Sierra de Gredos (Central Spain). Landscape Ecology 23, 657-672.

Viedma, O., Meliá, J., Segarra, D., García-Haro, J., 1997. Modeling rates of 
${ }_{849}$ ecosystem recovery after fires by using Landsat TM data. Remote Sensing 850 of Environment 61 (3), 383-398.

${ }_{851}$ White, J. D., Gutzwiller, K. J., Barrow, W. C., Randall, L. J., Swint, P., 852 2008. Modeling mechanisms of vegetation change due to fire in a semi-arid 853 ecosystem. Ecological Modelling 214 (2-4), 181-200.

${ }_{854}$ White, J. D., Ryan, K. C., Key, C. C., Running, S. W., 1996. Remote sens${ }_{855}$ ing of forest fire severity and vegetation recovery. International Journal of $856 \quad$ Wildland Fire 6 (3), 125-136. 


\section{Captions \& figures}

Fig. 1: Location of the study area and fraction tree cover per pixel (in percent) derived from MODIS vegetation continuous fields (VCF) of the year 2000. Additionally, the location of points discussed in Fig. 8 is indicated.

Fig. 2: Image overlay of (i) original Landsat NBR image at $30 \mathrm{~m}$ resolution at 10 October 2000 at the end of the fire season ( purple-dark blue), (ii) burnt pixels reected by their RMSD in the $\mathrm{TSS}_{R M S D}$ approach (cyan-yellow-red) and (iii) the set of selected control pixels (green) for all fire pixels.

Fig. 3: Illustration of the IpRI calculation, where (i) the dot-dash line represents the cubic spline fitted on the post-fire $\mathrm{pRI}^{t}$ time series, (ii) the moments $t_{0}$ and $t_{1}$ are displayed as dashed lines and (iii) the three IpRI estimates (IpRI1, IpRI2, IpRI3) are calculated from the shaded area using the original $\mathrm{pRI}^{t}$ values and $\mathrm{pRI}^{t}=1$.

Fig. 4: Comparison of the bi-temporally differenced Landsat dNBR and VGT dNDVI data: a) Landsat bi-temporal averaged dNBR values per $1 \mathrm{~km}^{2}$ for the Globscar burnt pixels, b) VGT bi-temporal dNDVI data for the same burnt pixels. In both figures, yellow-red colors indicate positive values, associated with decreased NBR and NDVI values one year after the fire. Cyanblue colors, on the other hand, reflect negative dNBR and dNDVI values, indicating a higher NBR or NDVI values one year after the fire. Additionally, the location of points discussed in Fig. 8 is indicated.

Fig. 5: Comparison of the control pixel based estimates of fire-vegetation impact based on pRI for Landsat NBR and VGT NDVI data: a) pRI for Landsat NBR values, b) pRI for VGT NDVI data. In both figures, yellowred colors indicate negative values, associated with decreased NBR and NDVI 
values with respect to the control pixels. Cyan-blue colors, on the other hand, reflect positive pRI values, indicating a higher NBR or NDVI values for the burnt pixels than for the control pixels. Additionally, the location of points discussed in Fig. 8 is indicated.

Fig. 6: Illustration of the difference in mean VGT NDVI (dNDVI) for the 1999-2000 and 2000-2001 November to April growing seasons for both burnt and control pixels, where control pixels are delineated in blue.

Fig. 7: Map of the three derived IpRI metrics derived from the VGT NDVI pRI $^{t}$ time series: a) the initial fire-vegetation impact (IpRI1), b) the increased vegetation greenness some time after the fire (IpRI2), c) the subsequent $\mathrm{pRI}^{t}$ drop after a short period of increased vegetation greenness (IpRI3).

Fig. 8: Illustration of the IpRI calculation for individual points in Figs. 1,45 , 7, where (i) the dot-dash line represents the cubic spline fitted on the post-fire $\mathrm{pRI}^{t}$ time series, (ii) the moments $t_{0}$ and $t_{1}$ are displayed as dashed lines and (iii) the IpRI estimates are calculated from the shaded area using the original $\mathrm{pRI}^{t}$ values and $\mathrm{pRI}^{t}=1$, and (iv) the April 2000 and 2001 Landsat image acquisition are represented by a small triangle: a) pt.1, b) pt.2, c) pt.3, d) pt.4, e) pt.5 . 


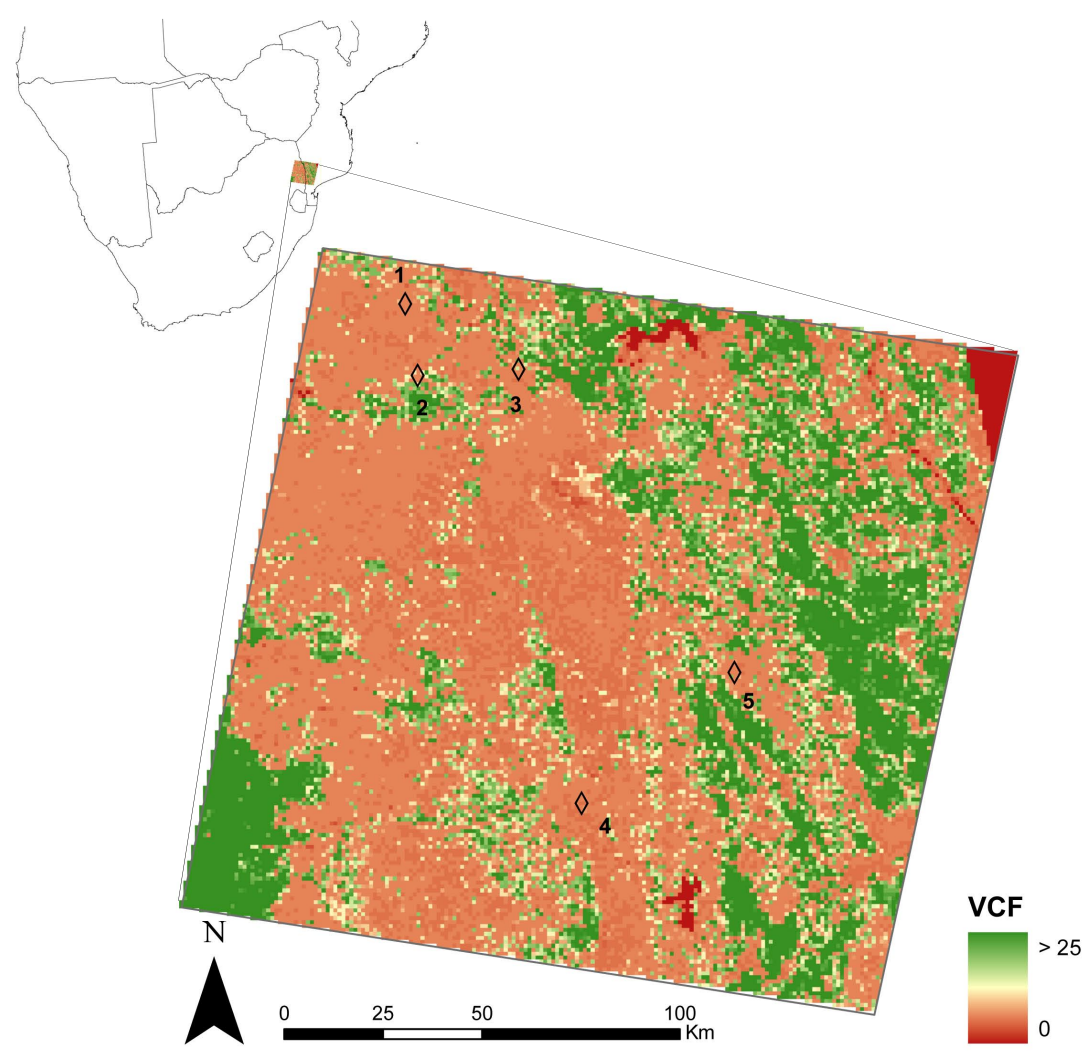

Figure 1: Location of the study area and fraction tree cover per pixel (in percent) derived from MODIS vegetation continuous fields (VCF) of the year 2000. Additionally, the location of points discussed in Fig. 8 is indicated. 


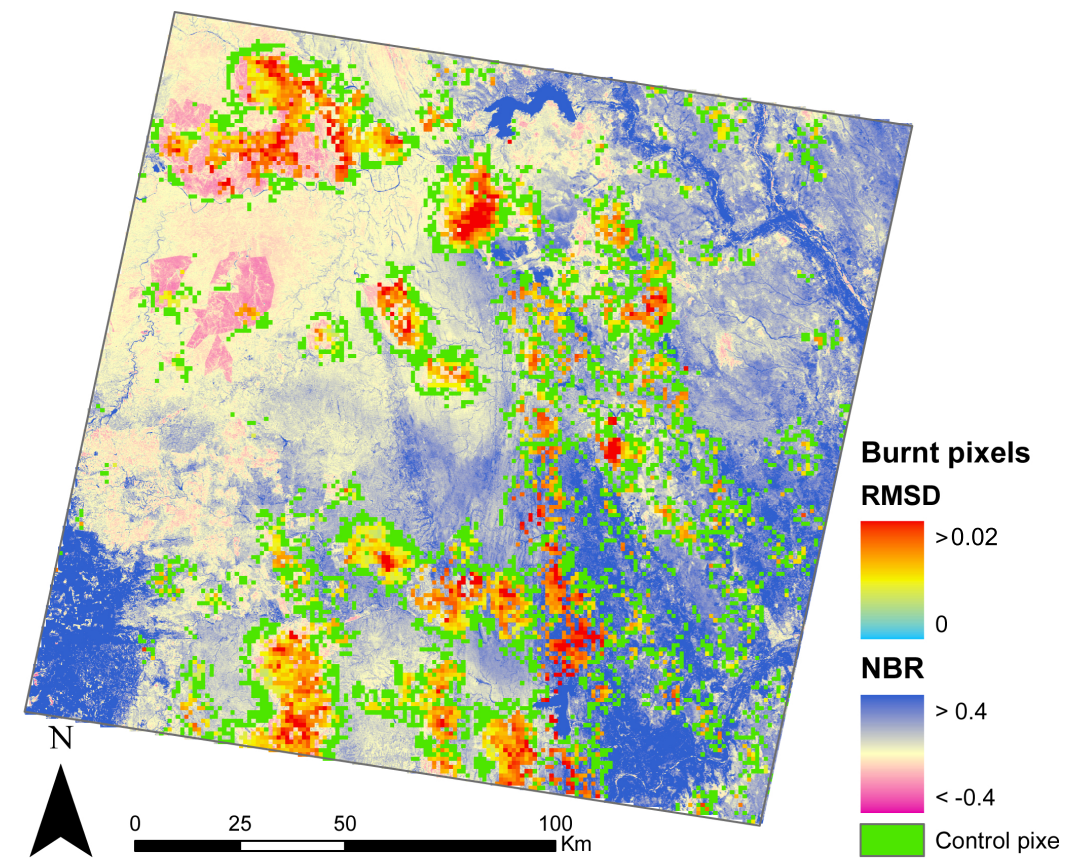

Figure 2: Image overlay of (i) original Landsat NBR image at $30 \mathrm{~m}$ resolution at 10 October 2000 at the end of the fire season ( purple-dark blue), (ii) burnt pixels reected by their RMSD in the $\operatorname{TSS}_{R M S D}$ approach (cyan-yellow-red) and (iii) the set of selected control pixels (green) for all fire pixels. 


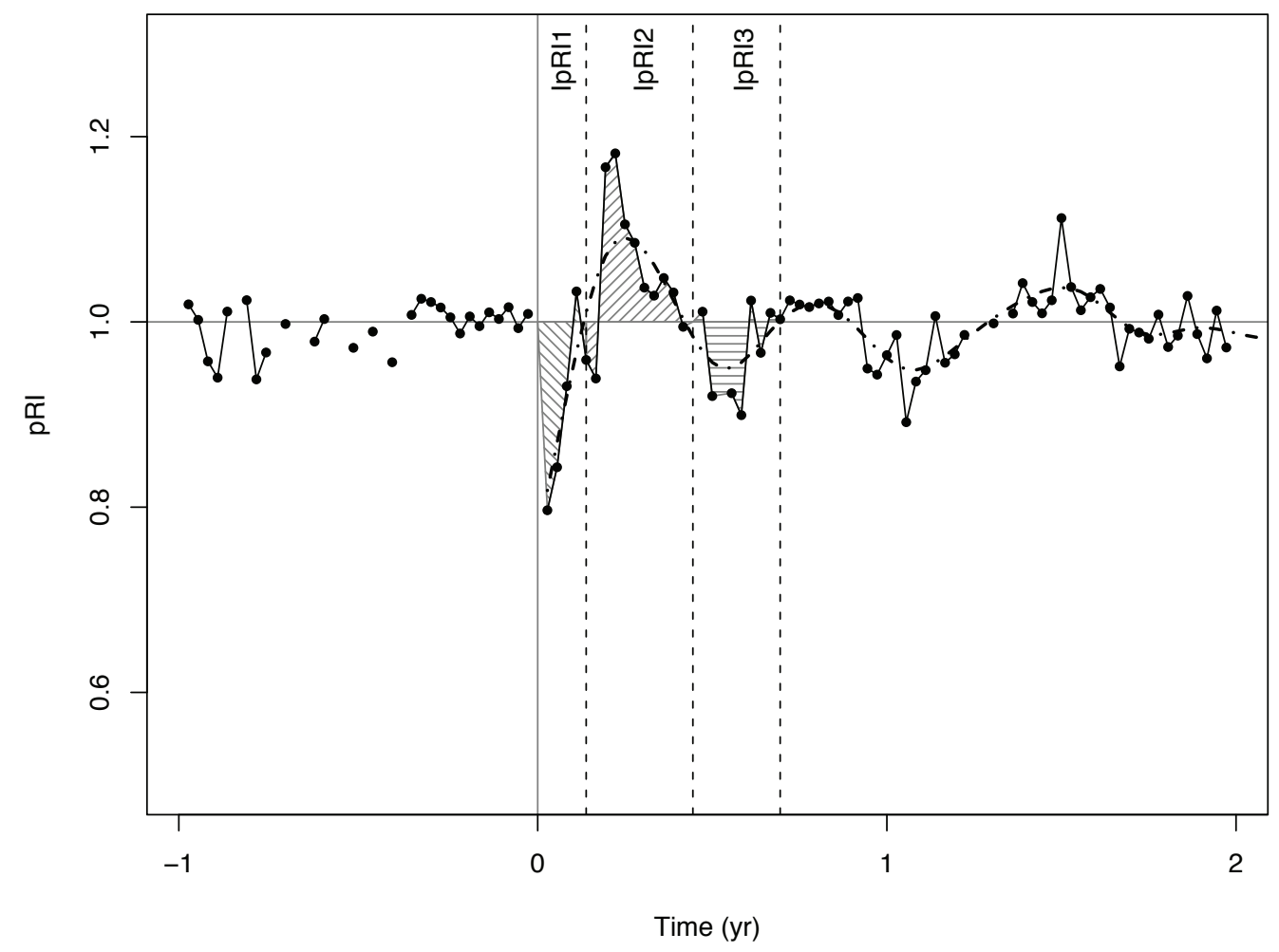

Figure 3: Illustration of the IpRI calculation, where (i) the dot-dash line represents the cubic spline fitted on the post-fire $\mathrm{pRI}^{t}$ time series, (ii) the moments $t_{0}$ and $t_{1}$ are displayed as dashed lines and (iii) the three IpRI estimates (IpRI1, IpRI2, IpRI3) are calculated from the shaded area using the original $\mathrm{pRI}^{t}$ values and $\mathrm{pRI}^{t}=1$. 


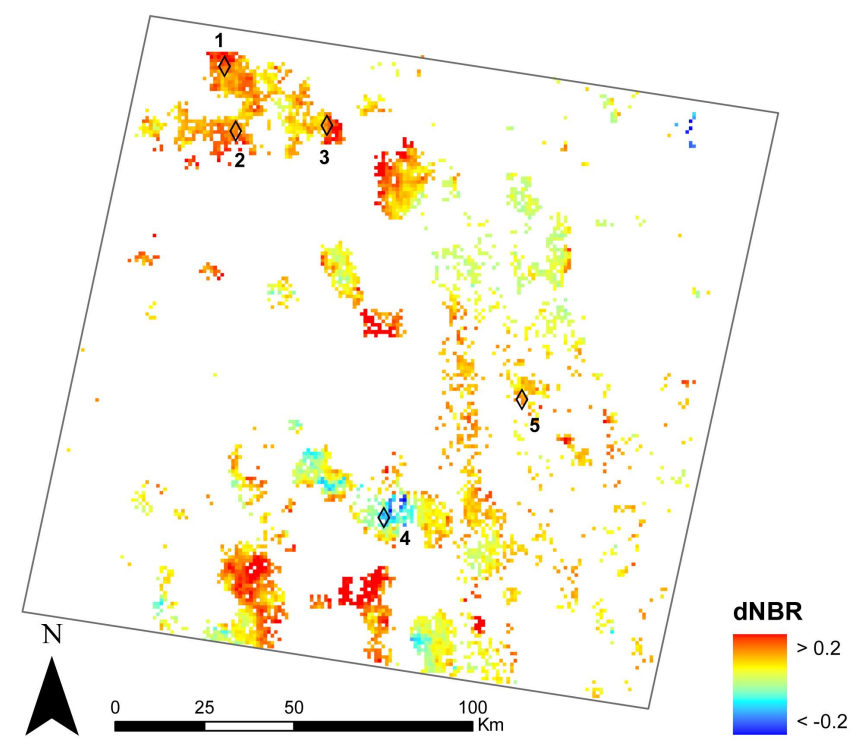

(a)

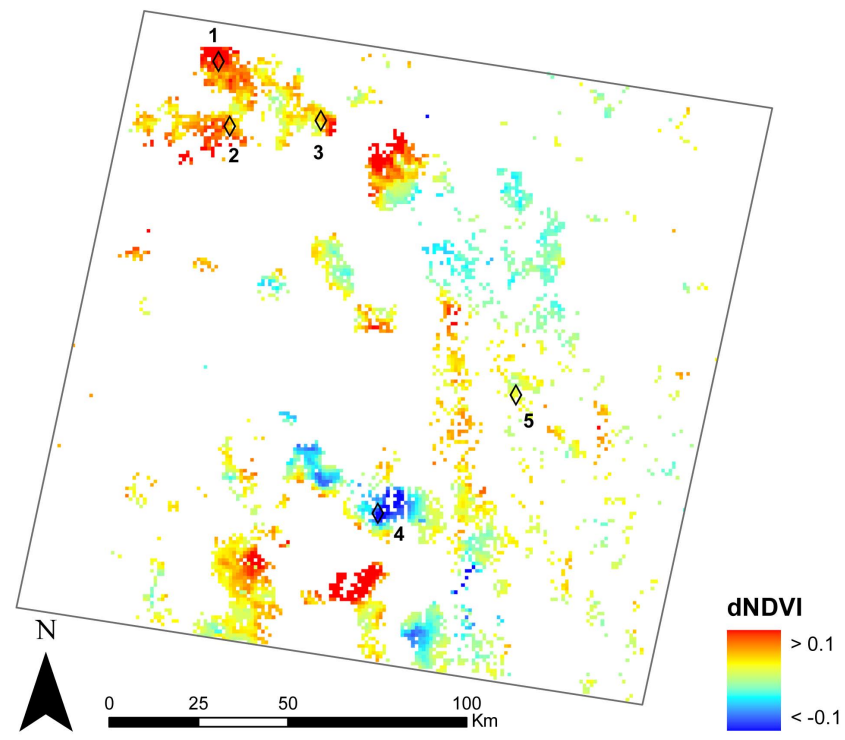

(b)

Figure 4: Comparison of the bi-temporally differenced Landsat dNBR and VGT dNDVI data: a) Landsat bi-temporal averaged dNBR values per $1 \mathrm{~km}^{2}$ for the Globscar burnt pixels, b) VGT bi-temporal dNDVI data for the same burnt pixels. In both figures, yellowred colors indicate positive values, associated with decreased NBR and NDVI values one year after the fire. Cyan-blue colors, on the other hand, reflect negative dNBR and dNDVI values, indicating a higher NBR or NDVI values one year after the fire. Additionally, the location of points discussed in Fig. 8 is indicated. 


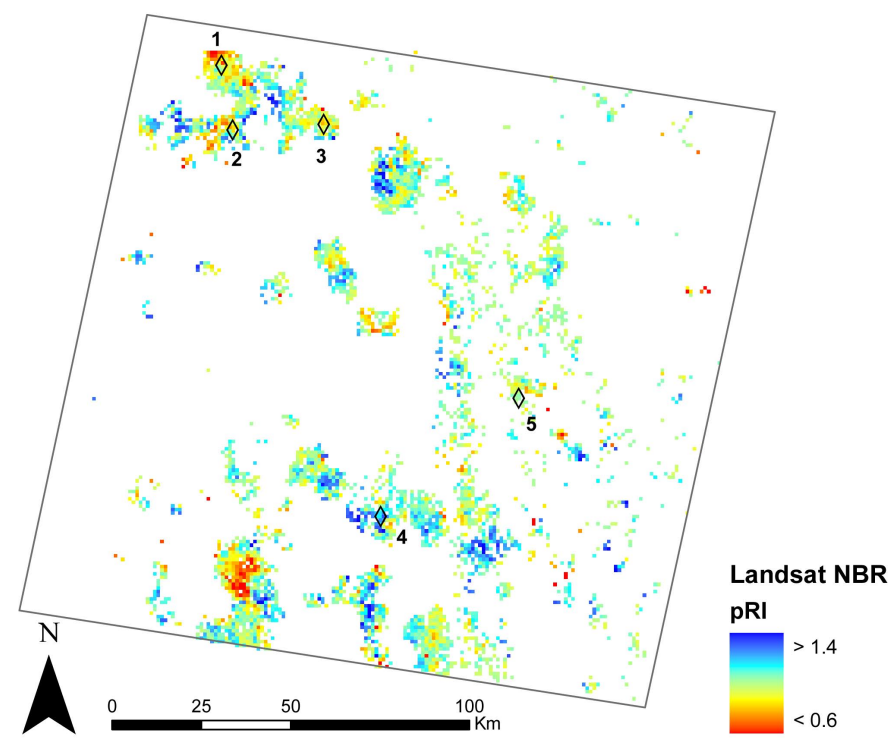

(a)

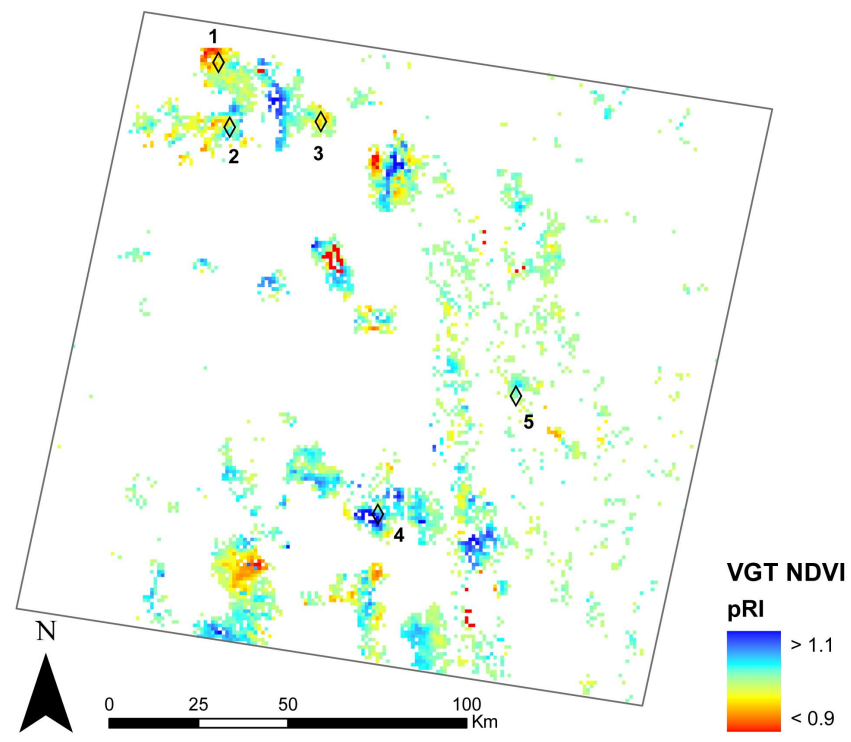

(b)

Figure 5: Comparison of the control pixel based estimates of fire-vegetation impact based on pRI for Landsat NBR and VGT NDVI data: a) pRI for Landsat NBR values, b) pRI for VGT NDVI data. In both figures, yellow-red colors indicate negative values, associated with decreased NBR and NDVI values with respect to the control pixels. Cyan-blue colors, on the other hand, reflect positive pRI values, indicating a higher NBR or NDVI values for the burnt pixels than for the control pixels. Additionally, the location of points discussed in Fig. 8 is indicated. 


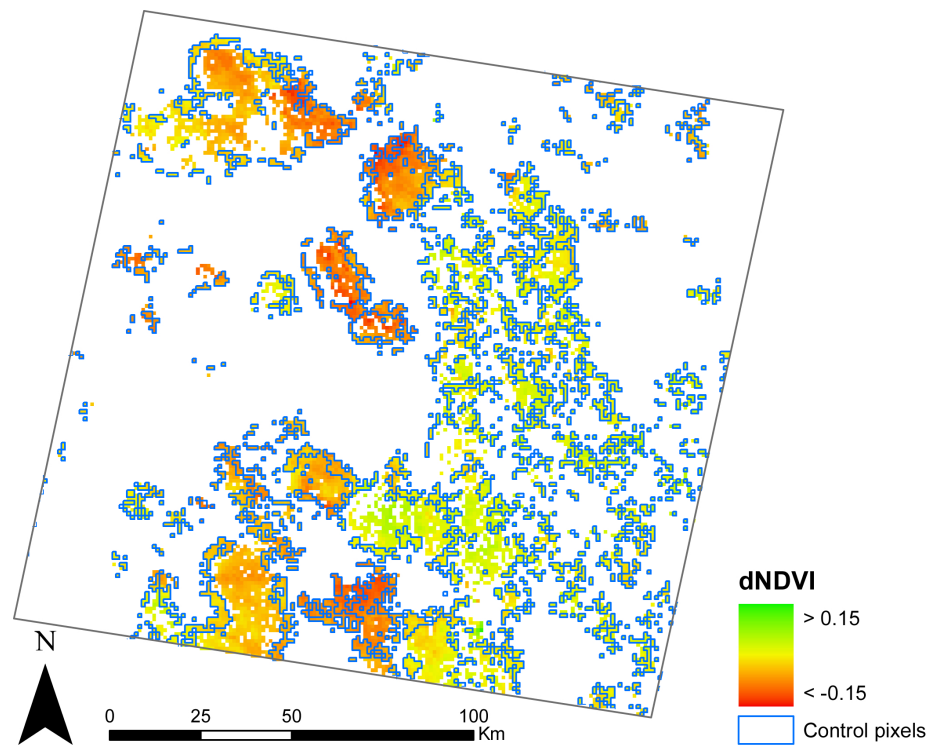

Figure 6: Illustration of the difference in mean VGT NDVI (dNDVI) for the 1999-2000 and 2000-2001 November to April growing seasons for both burnt and control pixels, where control pixels are delineated in blue. 


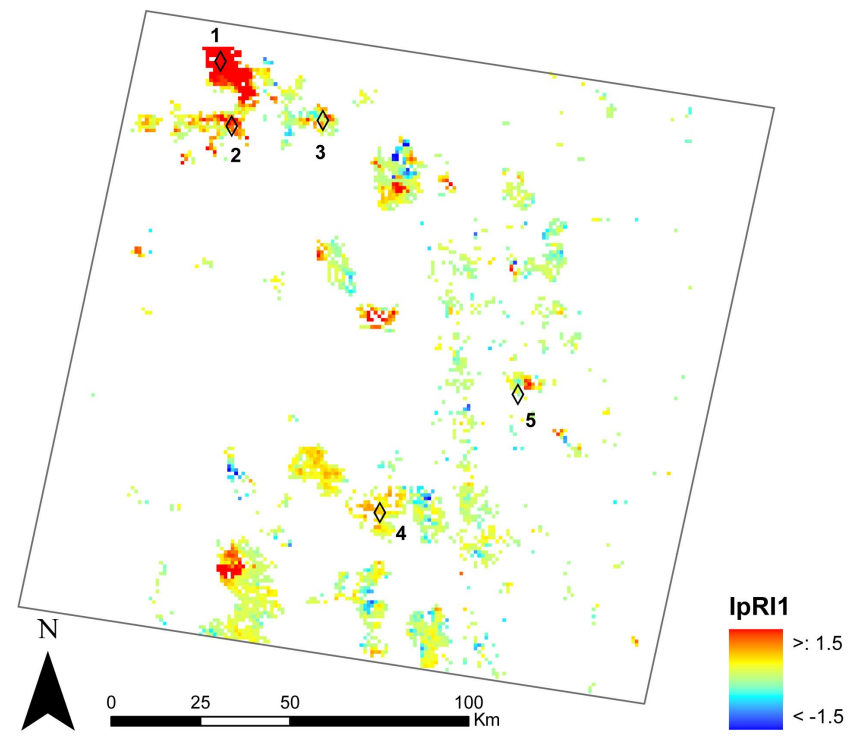

(a)

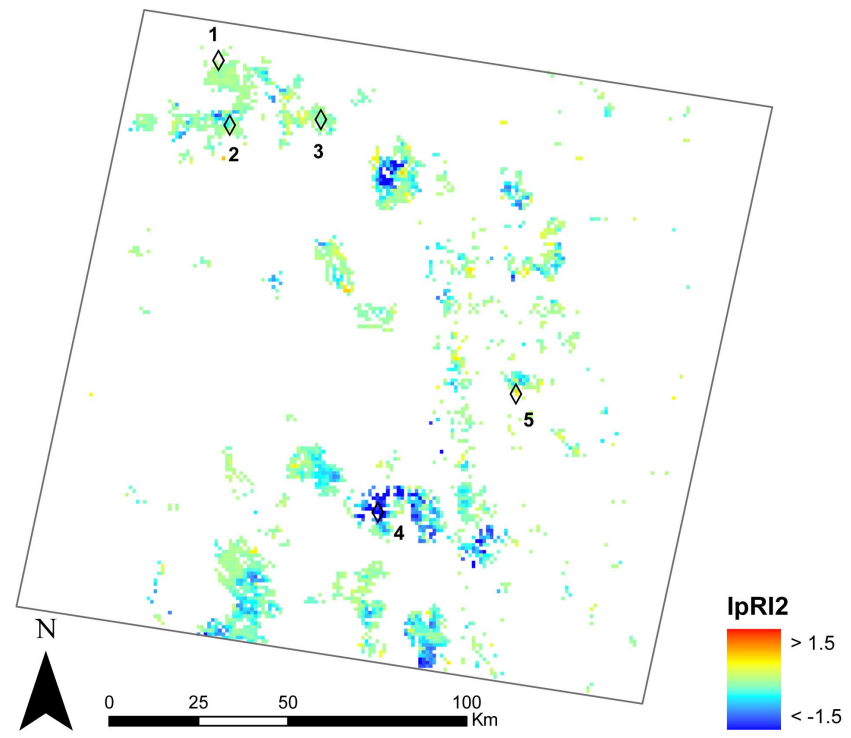

(b)

Figure 7: Map of the three derived IpRI metrics derived from the VGT NDVI pRI ${ }^{t}$ time series: a) the initial fire-vegetation impact (IpRI1), b) the increased vegetation greenness some time after the fire (IpRI2). Additionally, the location of points discussed in Fig. 8 is indicated. 


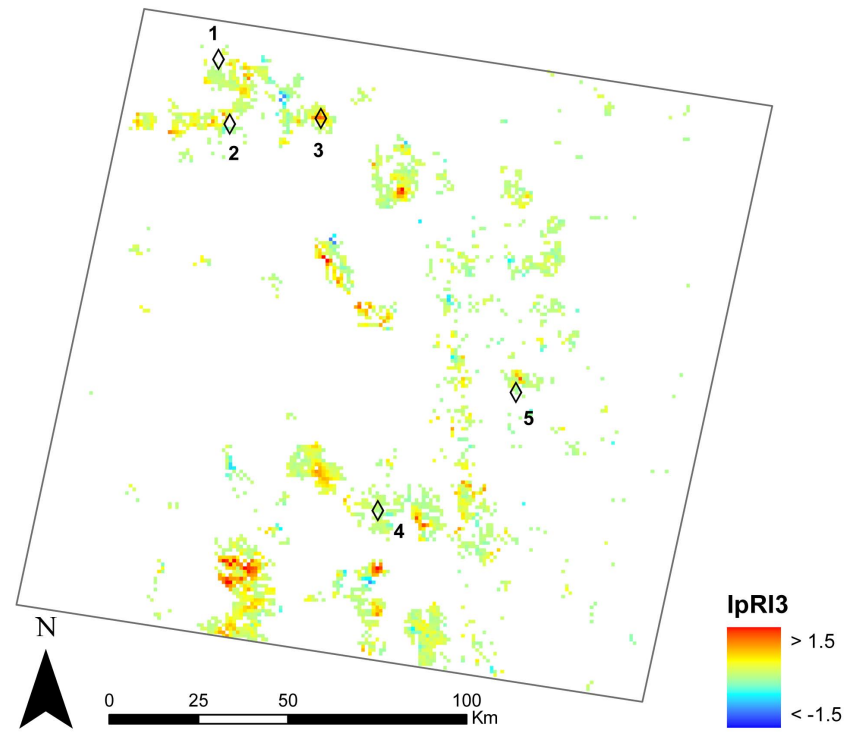

(c)

Figure 7: Map of the three derived IpRI metrics derived from the VGT NDVI pRI ${ }^{t}$ time series [cont.]: c) the subsequent $\mathrm{pRI}^{t}$ drop after a short period of increased vegetation greenness (IpRI3). Additionally, the location of points discussed in Fig. 8 is indicated. 


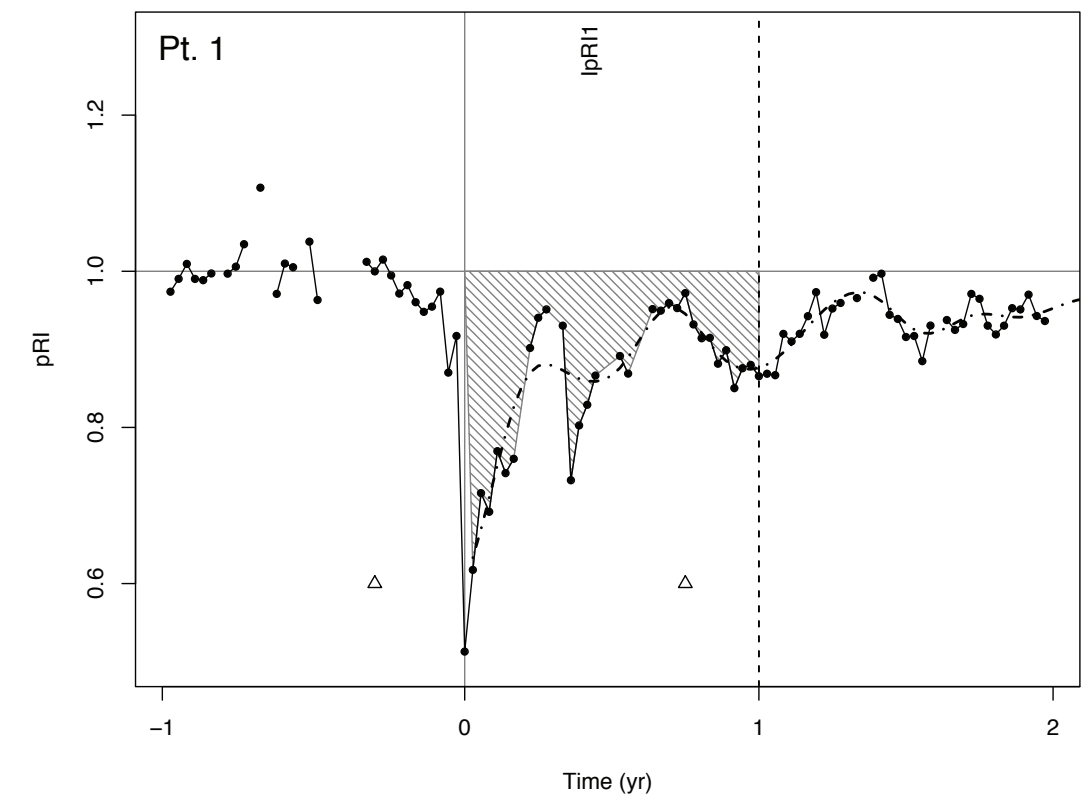

(a)

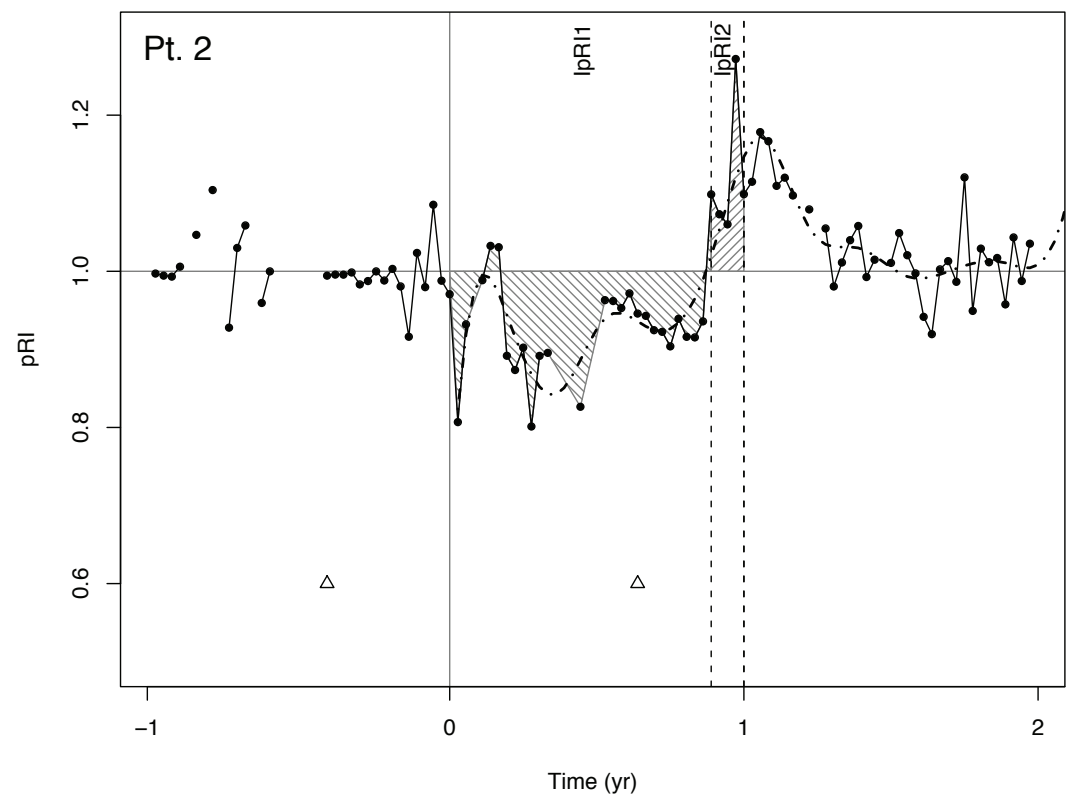

(b)

Figure 8: Illustration of the IpRI calculation for individual points in Figs. 1,4-5, 7, where (i) the dot-dash line represents the cubic spline fitted on the post-fire $\mathrm{pRI}^{t}$ time series, (ii) the moments $t_{0}$ and $t_{1}$ are displayed as dashed lines and (iii) the IpRI estimates are calculated from the shaded area using the original $\mathrm{pRI}^{t}$ values and $\mathrm{pRI}^{t}=1$, and (iv) the April 2000 and 2001 Landsat image acquisition are represented by a small triangle: a) pt.1, b) pt.2 


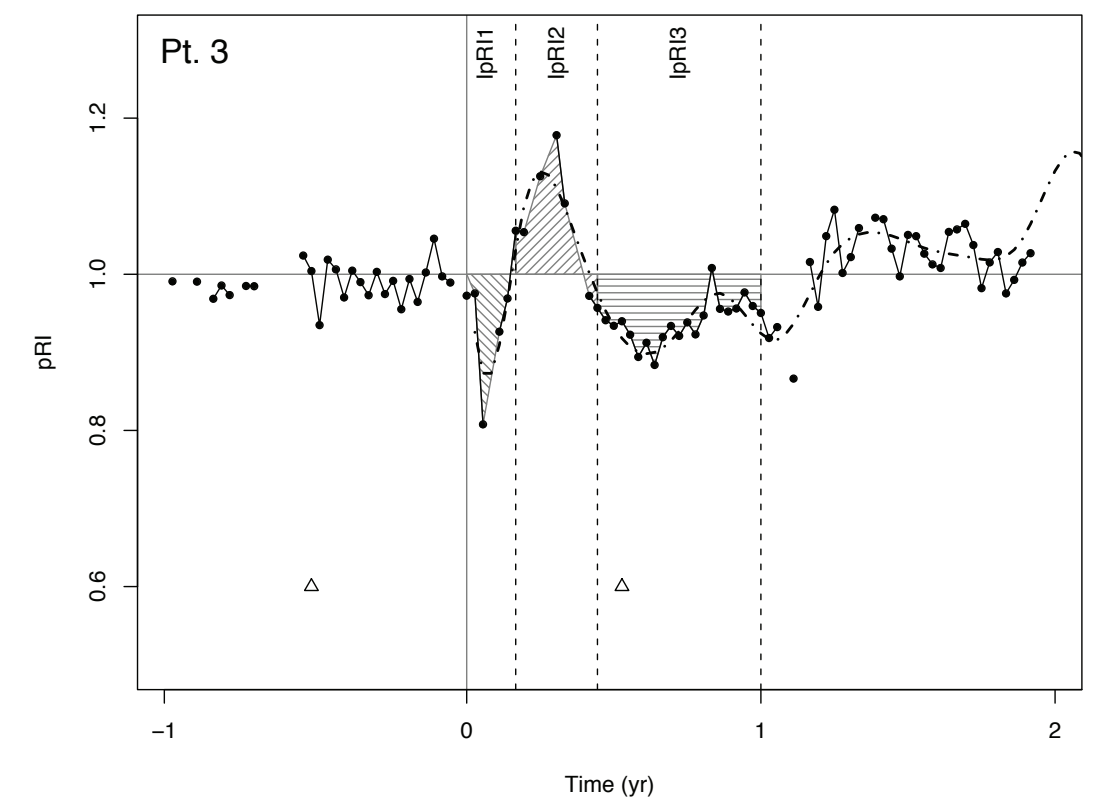

(c)

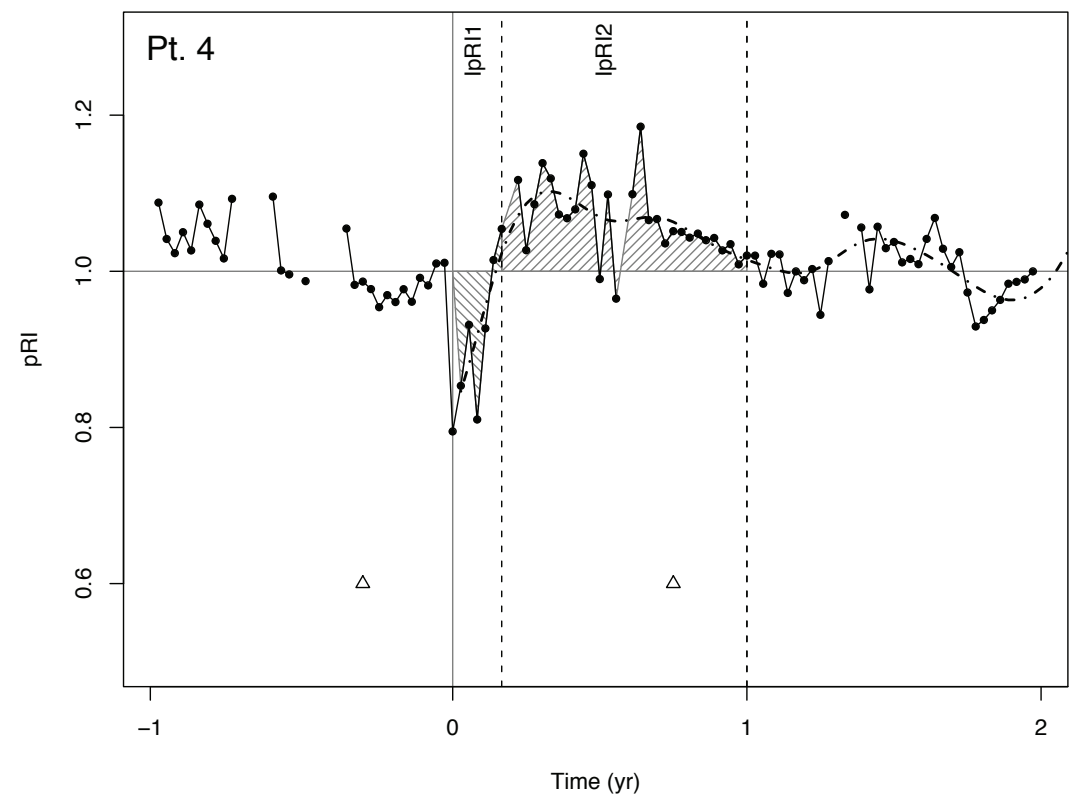

(d)

Figure 8: [Cont.] Illustration of the IpRI calculation for individual points in Figs. 1,4-5, 7, where (i) the dot-dash line represents the cubic spline fitted on the post-fire pRI ${ }^{t}$ time series, (ii) the moments $t_{0}$ and $t_{1}$ are displayed as dashed lines and (iii) the IpRI estimates are calculated from the shaded area using the original $\mathrm{pRI}^{t}$ values and $\mathrm{pRI}^{t}=1$, and (iv) the April 2000 and 2001 Landsat image acquisition are represented by a small triangle: c) pt.3, d) pt.4. 


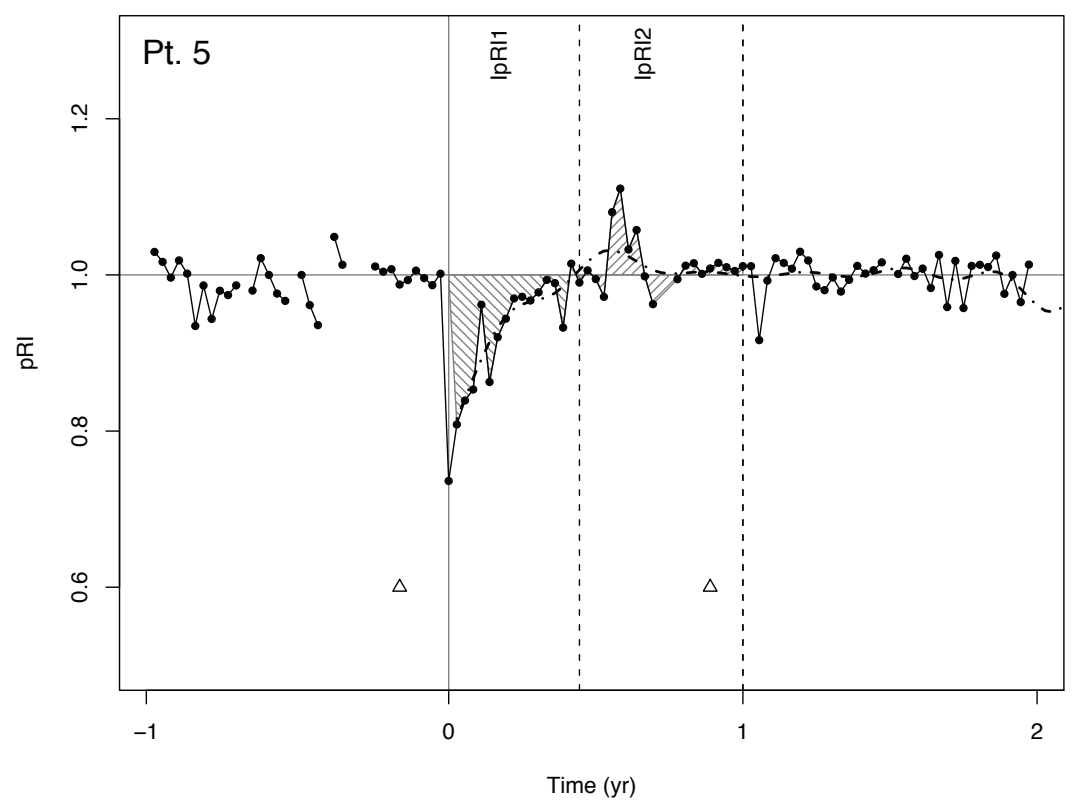

(e)

Figure 8: [Cont.] Illustration of the IpRI calculation for individual points in Figs. 1,4-5, 7 , where (i) the dot-dash line represents the cubic spline fitted on the post-fire $\mathrm{pRI}^{t}$ time series, (ii) the moments $t_{0}$ and $t_{1}$ are displayed as dashed lines and (iii) the IpRI estimates are calculated from the shaded area using the original $\mathrm{pRI}^{t}$ values and $\mathrm{pRI}^{t}=1$, and (iv) the April 2000 and 2001 Landsat image acquisition are represented by a small triangle: e) pt.5 